Annales Geophysicae (2002) 20: 2047-2066 (C) European Geosciences Union 2002

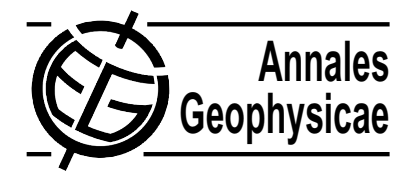

\title{
Numerical study of the October 2000 torrential precipitation event over eastern Spain: analysis of the synoptic-scale stationarity
}

\author{
V. Homar ${ }^{1}$, R. Romero ${ }^{1}$, C. Ramis ${ }^{1}$, and S. Alonso ${ }^{1,2}$ \\ ${ }^{1}$ Meteorology Group, Dept. de Física, Univ. de les Illes Balears, Palma de Mallorca, Spain \\ ${ }^{2}$ IMEDEA, UIB-CSIC, Palma de Mallorca, Spain
}

Received: 24 August 2001 - Revised: 15 March 2002 - Accepted: 26 March 2002

\begin{abstract}
A torrential precipitation event affected eastern Spain during 21 to 24 October 2000. Total accumulated rainfall higher than $500 \mathrm{~mm}$ was registered at some locations, with values up to $300 \mathrm{~mm}$ in a 24 -h period. The synopticscale charts for these days show the presence of a cold cutoff low aloft, south of the Iberian Peninsula, as a part of an $\Omega$-blocking structure over Europe. At low levels, persistent easterly winds, established between a dominant anticyclone over eastern Europe and a cyclone over Morocco, are found over the western Mediterranean throughout the entire period. Satellite images show the advance and breaking away of a trough, with an associated cold front, over the Iberian Peninsula, which resulted in the cutoff low formation. Later, scattered convective cells are detected along the eastern Spanish coast during more than 3 days. Numerical simulations reveal that the convective environment was developed by the lowlevel advection of warm and moist air from central Mediterranean, being charged of moisture by evaporation from the sea. Sensitivity runs confirm that the synoptic-scale persistent low-level easterly flow, and specifically, the presence of a low level jet, was crucial for the subsynoptic processes leading to the long lasting torrential rainfall over the exposed terrains of eastern Spain. The stagnancy of the low-level flow is attributed to the quasi-stationary characteristics of the upper level cutoff low located south of the Iberian Peninsula. Experiments with modified upper-level potential vorticity distributions reveal that slight deviations from the observed configuration result in enhanced mobility of the low-level flow pattern, and thereby a reduction of the precipitation persistence. This suggests the major importance of a correct representation in the model initial conditions of the intensity and location of the upper level features, in order to obtain valuable numerical forecasts of these heavy rainfall events.
\end{abstract}

Key words. Meteorology and atmospheric dynamics (convective processes; mesoscale meteorology; precipitation)

Correspondence to: V. Homar (victor.homar@uib.es)

\section{Introduction}

Severe moist convective episodes occur frequently in autumn over the western Mediterranean area (see Fig. 1 for the locations referred to in the text), and particularly, in eastern Spain (Font, 1983; Romero et al., 1998a). A schematic conceptual model which explains the meteorological processes involved in these events has been widely discussed (e.g. García-Dana et al., 1982; Llasat, 1987; Ramis et al., 1994). In essence, during the autumn the relatively warm sea surface heats and moistens the low levels and, together with the entrance of upper-level cold Atlantic disturbances, contributes to convectively destabilize the lower troposphere. Under these conditions, weak mesoscale lifting mechanisms are enough for triggering convection. Processes such as orographic upslope (Romero et al., 1998b), boundary layer convergence zones (Ramis et al., 1998), outflows from pre-existing convective systems and ageostrophic circulations associated with jetstreaks (Homar et al., 1999) have been described as the main contributors in the western Mediterranean to provide the necessary lifting to the low-level parcels to achieve the level of free convection. Further, continuous supply of moisture at low levels to the convective areas is required to sustain the convection and to produce large rainfall amounts. The warming and moistening of the low levels in heavy rainfall episodes of eastern Spain is usually favored by particular surface winds which advect warm air from north Africa over the warm Mediterranean. On the other hand, the role of the upper levels cyclonic disturbance, present in most of the cases, is twofold. First, it introduces cold and humid air to the midtropospheric levels and second, it enhances (or at least does not oppose to) subsynoptic upward motion. A pragmatic application of this conceptual model, which can be of value to weather forecasters, is the flood forecasting methodology based on ingredients (Doswell III et al., 1996). This methodology identifies areas of possible convective developments by searching for the simultaneous presence of the favorable synoptic-scale ingredients for heavy rainfall, namely convective or latent instability, low-level moisture flux convergence, 

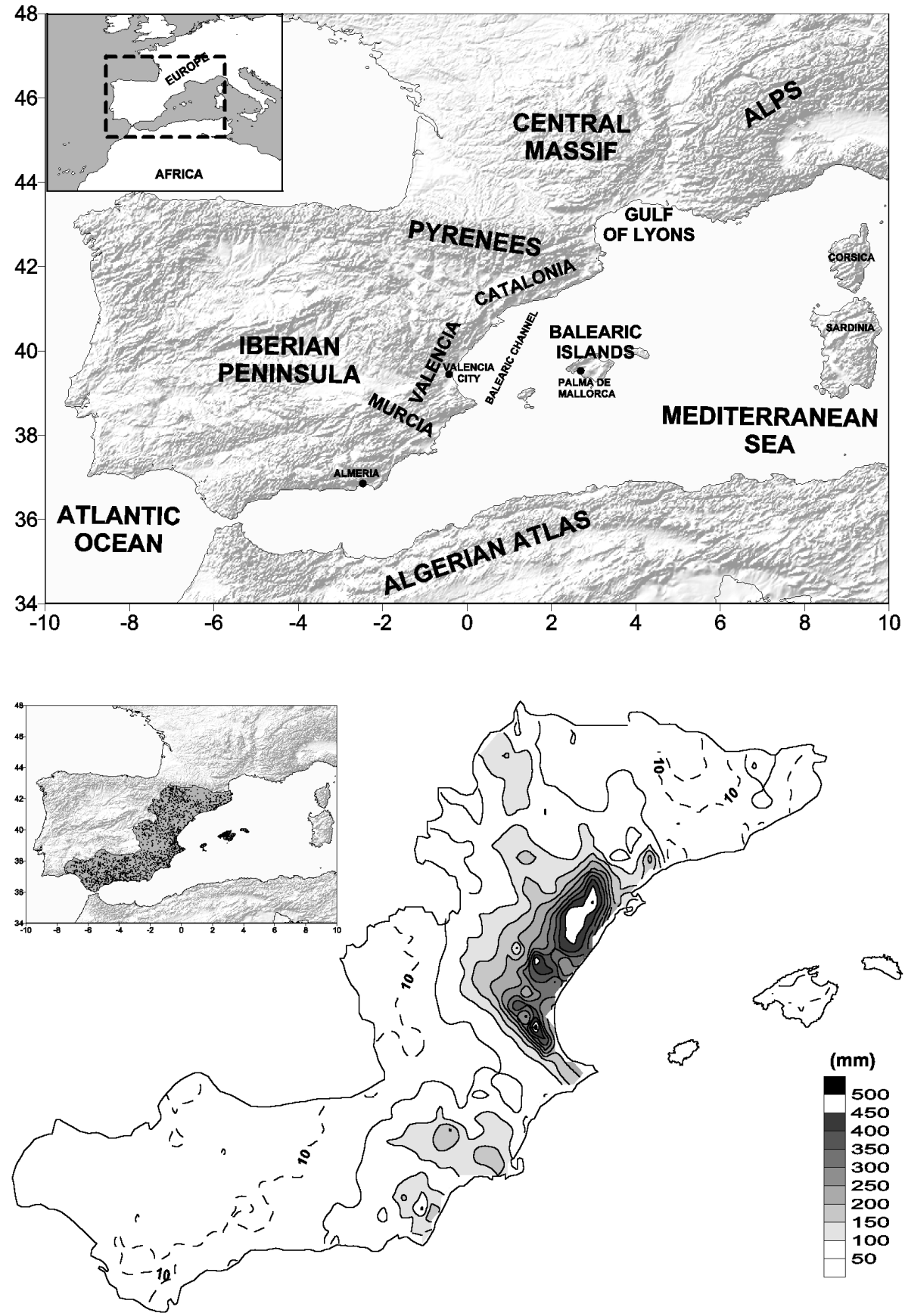

Fig. 1. The western Mediterranean area. The map includes locations referred to in the text.
Fig. 2. Analysis of the 21-24 October rain-gage precipitation $(\mathrm{mm})$. The top left corner map indicates the area and the location (dots) of the 1967 stations used to perform the analysis. high values of precipitable water and quasi-geostrophic forcing for upward motion. Mesoscale processes initiate the convection by focusing those ingredients in specific areas and providing lifting to the low-tropospheric parcels (Doswell III, 1987).

The episode considered in the present study occurred during the days 21-24 October 2000 over eastern Spain. Total rainfall amounts in excess of $500 \mathrm{~mm}$ were registered in the locations of Valencia and Catalonia (Fig. 2). Serious floodings produced 8 fatalities, as well as critical damages to fruit crops and populated areas. Roads and railways of the area were damaged and the total economical loss estimated by insurance companies was $100 \mathrm{M} €$. The synoptic-scale meteorological setting of the event is characterized mainly by the presence of a cold cutoff low aloft, south of the Iberian Peninsula, and an easterly maritime flow toward the Spanish coast at low levels. The situation was very stationary (45 days) and therefore ensured a continuous moisture supply and convective instability replenishment.

Romero et al. (2000) study the meteorological settings that led to the high stationarity and efficiency of the convective systems responsible for two catastrophic flash flood events in eastern Spain. They highlight that the presence of a coldcore closed low at mid to upper levels and the interaction of 


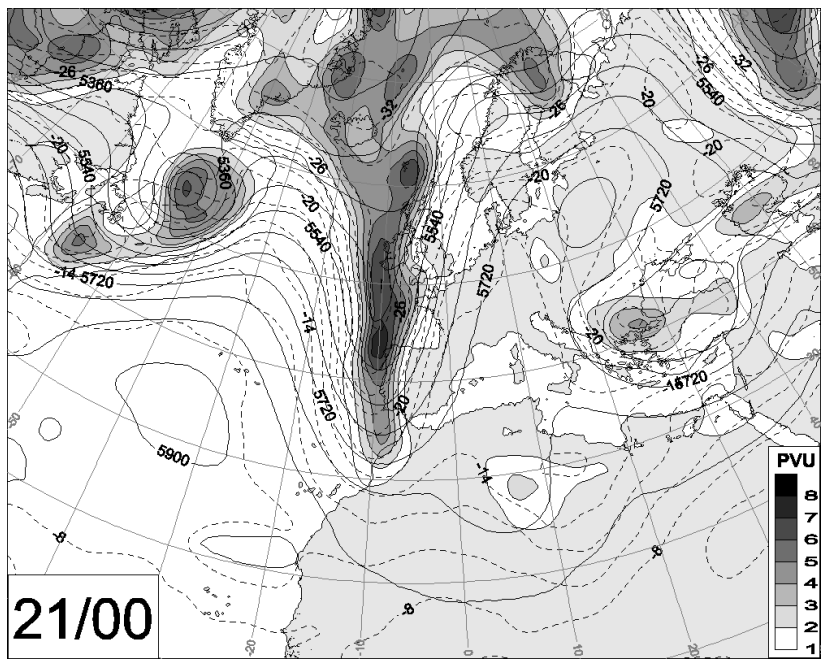

(a)

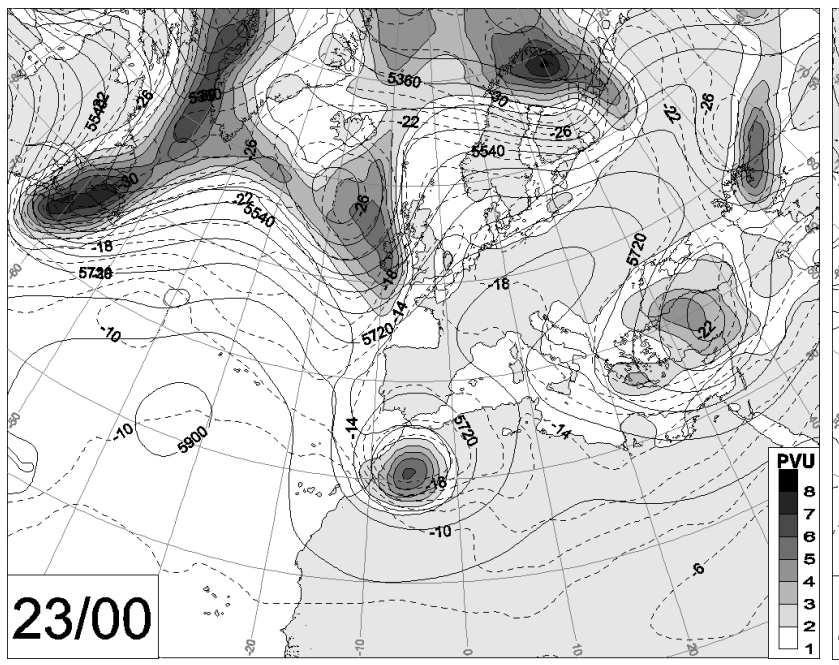

(c)

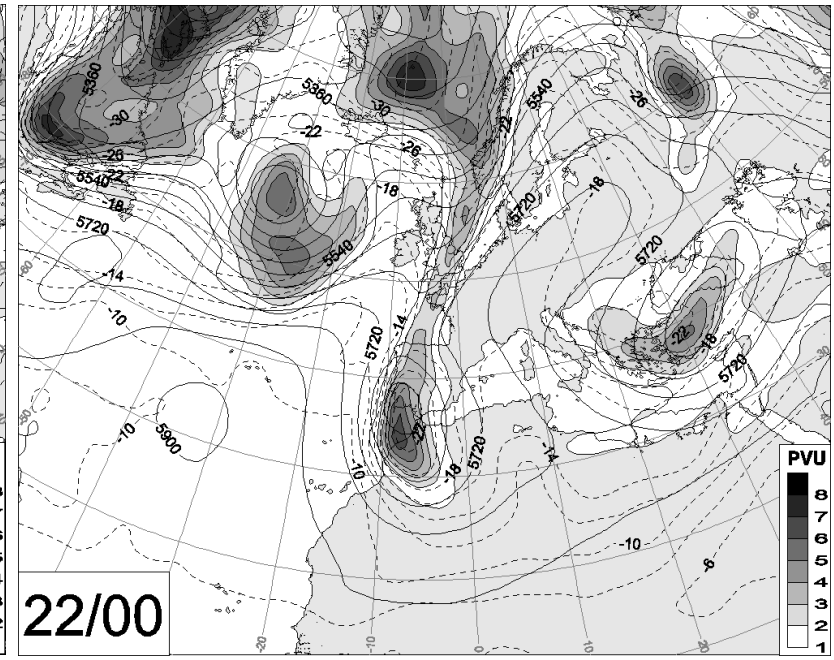

(b)

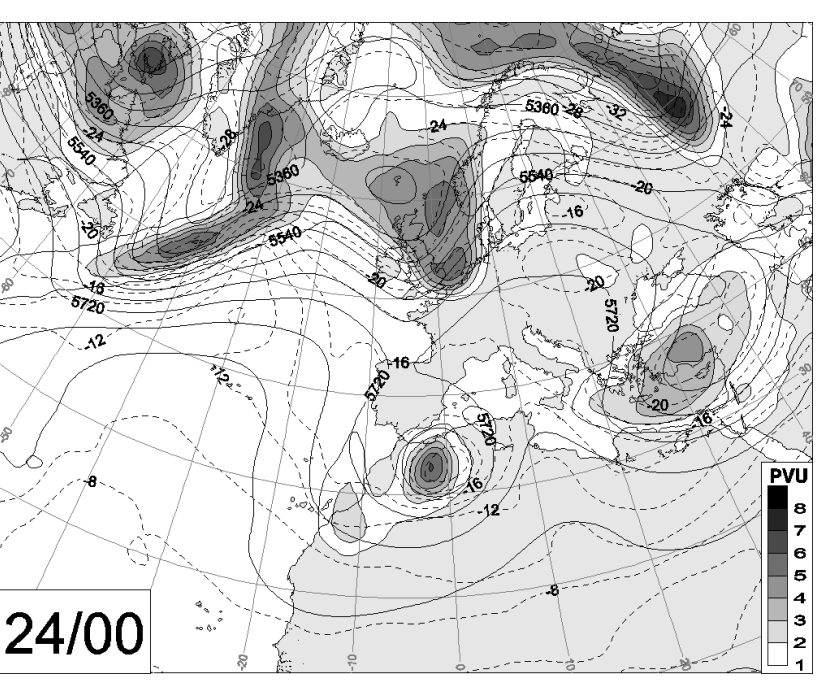

(d)

Fig. 3. Potential vorticity (PVU, shaded contours) at $300 \mathrm{hPa}$, geopotential height (gpm, solid line) and temperature $\left({ }^{\circ} \mathrm{C}\right.$, dashed line) at $500 \mathrm{hPa}$ on 00:00 UTC (a) 21, (b) 22, (c) 23, (d) 24 October 2000, as diagnosed from the NCEP analysis.

a long fetch of easterly flow over the Mediterranean Sea with the local orography were determinant for the heavy rainfall production. Although the two cases studied by Romero et al. (2000) present significant differences at mid and upper levels, the immobile and long lasting character of the convective area is shown to be linked to the low-level easterly flow persistency.

The main scope of this study is the identification of the large-scale factors leading to the stationarity of this event and the analysis of the particular consequences of such a situation in the western Mediterranean basin. Numerical simulations are used to investigate the synoptic-scale and mesoscale aspects of the event. Particular attention is paid to the processes responsible for the setup and maintenance of the high moisture contents at all tropospheric levels off the Spanish coast. The role of the orographic ranges which configure the western Mediterranean basin on this event is studied. The sensitivity of the low-level flow stagnancy to slight modifications of the initial conditions will also be analyzed. In addition, the role of upper-level potential vorticity (PV) anomalies of particular interest on the evolution of the cutoff low is studied.

Analysis of the observations available for the event are analyzed in Sect. 2. Section 3 presents the numerical experiments characteristics, as well as the results obtained from the control run. The role of the upper-level features, the oro- 
graphic ranges and the evaporation from the sea on the heavy rainfall genesis is discussed in Sect. 4. An analysis of upper level stationarity is presented in Sect. 5. Final remarks and conclusions are presented in Sect. 6 .

\section{Observations}

An overview of the available observations for the event is presented, including the National Center for Environmental Prediction (NCEP) analyses, Meteosat satellite images and rain-gage precipitation analyses.

The NCEP analyses data set is provided on a $2.5^{\circ}$ grid at standard pressure levels every $12 \mathrm{~h}$. An inspection of the analyses shows the formation of an upper-level cutoff low during 21-22 October about the Iberian Peninsula. Figure 3 shows the $\mathrm{PV}$ as diagnosed from the analyses at $300 \mathrm{hPa}$ for 21 to 24 October 2000. An intense north-south PV streamer is present west of Europe at 21/00 (hereafter dates will be noted as $\mathrm{DD} / \mathrm{HH}$, referring to $\mathrm{HH}: 00$ UTC hours of day DD). Different evolution of the northern and southern halves of the PV structure produced the breaking away of the southern half, resulting in a closed cutoff. The northern half of the PV filament evolved quickly to the northeast, whereas the southern one remained more to the west, with a maximum of 6 PVU (1 PVU $\left.=10^{-6} \mathrm{Km}^{2} \mathrm{~s}^{-1} \mathrm{~kg}^{-1}\right)$ southwest of the Iberian Peninsula on 22/00 (Fig. 3b). The associated structures at $500 \mathrm{hPa}$ show the breaking away of the cold trough, and the formation of the cutoff cyclone. The following hours, 23/00 in Fig. 3c, the cold cutoff remained immobile south of the Iberian Peninsula with nearly a circular shape, outlining the western half of an $\Omega$-blocking structure centered over Europe. The cutoff achieved its maximum intensity on 23/12 exceeding $8 \mathrm{PVU}$ at $300 \mathrm{hPa}$. After this time, the cutoff started weakening but remained quasi-stationary (Fig. 3d), with only a slow advance eastwards. In total, the cold cutoff cyclone lasted for more than 4 days to the south of the Iberian Peninsula. The low-level correspondence to the steadiness at the upper levels can be observed in Fig. 4. The situation was dominated by prominent anticyclones located over eastern Europe and Atlantic, respectively, and a growing depression over Morocco, which developed as the upper level cutoff low formed and remained steady. An orographic sea level pressure modification, similar to that described by Homar et al. (1999), is detected over the Algerian coast at 23/00 (Fig. 4b), producing an enhancement and a northwards shifting of the easterly flow toward the Spanish coast. Easterly flow inducing warm advection over eastern Spain is present over the Mediterranean in response to the surface pressure pattern. It is remarkable the long fetch over the sea which is followed by the surface parcels before reaching the eastern Spanish coastal lands. This warm and moist easterly flow lasted for more than 4 days.

The Meteosat satellite infrared imagery show the entrance during 20 and 21 October of a clear cold front cloud pattern accompanying the cutoff-precursor trough, which is broken at about the Pyrenees latitude by 21/12 (not shown). The

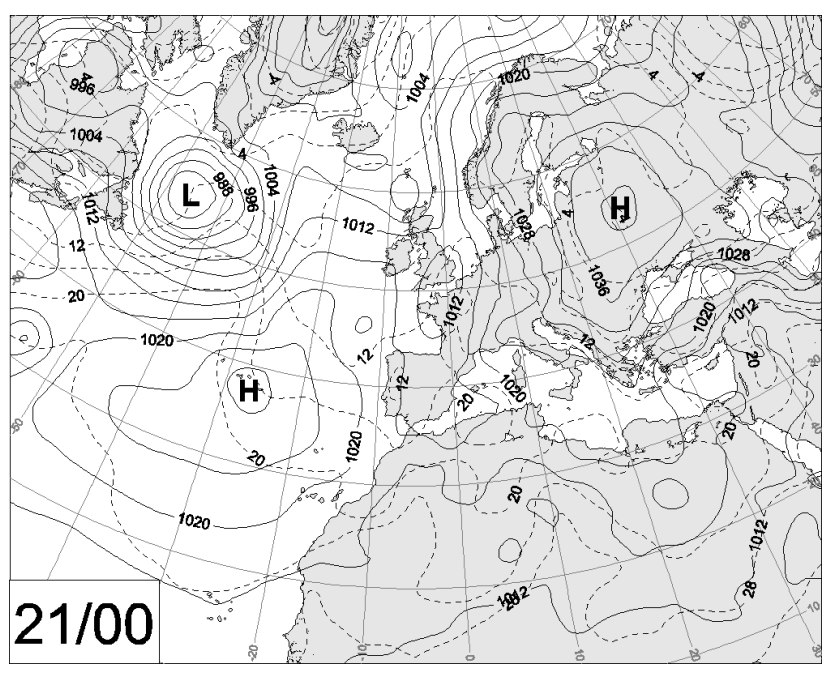

(a)

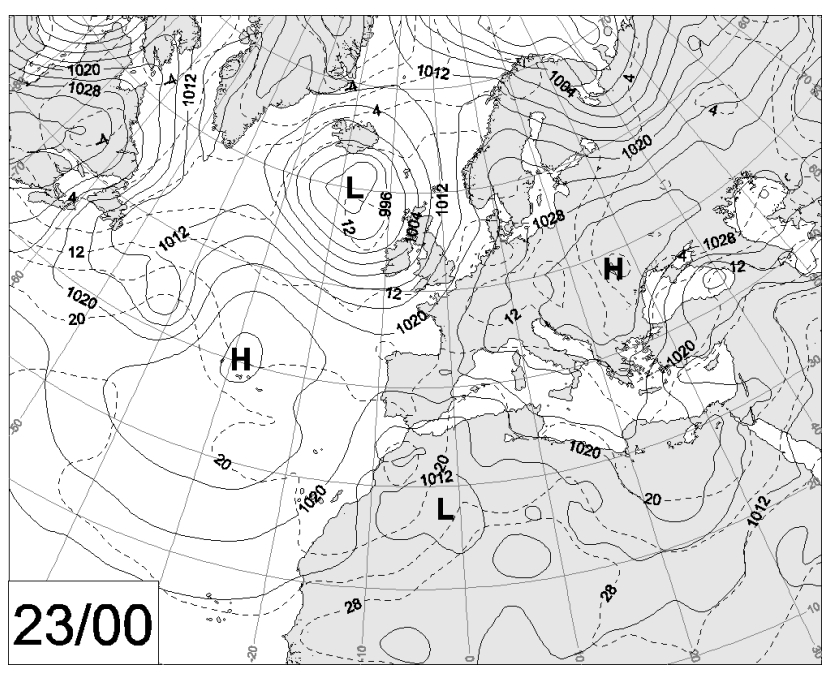

(b)

Fig. 4. Temperature at $925 \mathrm{hPa}\left({ }^{\circ} \mathrm{C}\right.$, dashed line) and sea level pressure (hPa, solid line) obtained from the NCEP analysis on 00:00 UTC (a) 21 and (b) 23 October 2000.

following hours, 22/12 in Fig. 5a, cyclonic circulation at the upper levels is clearly deducible south of the Iberian Peninsula, and the entrance of a new frontal system from the northwest is also identifiable at the top left corner of the image. Over the western Mediterranean Sea, southeast to northwest oriented low-level cloudy bands delineate the flow, which impinges over an area with notable convective activity. At this time, scattered convection is present over the Balearic Islands, and the Catalonia and Valencia regions. The following hours, convective activity with similar characteristics is present over Mediterranean Spain. At 23/12 (Fig. 5b), an analogous cloudy pattern to the 24-h prior image is observed, with evidence of the cyclonic circulation aloft, together with 


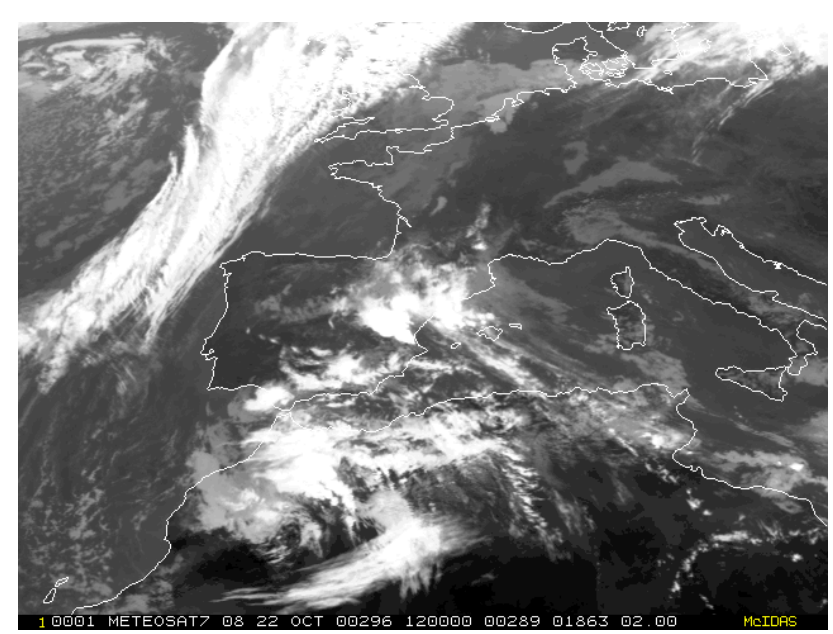

(a)

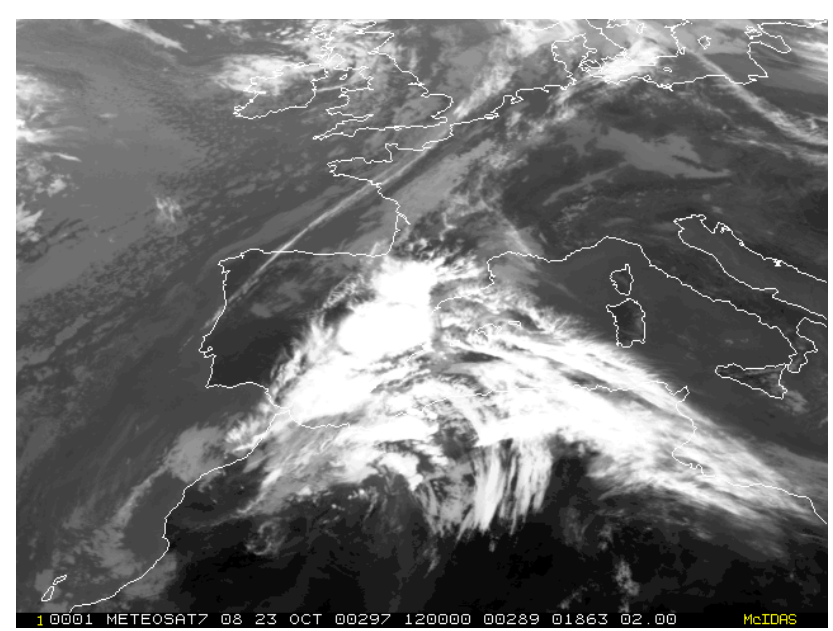

(b)

Fig. 5. Meteosat satellite infrared images on 12:00 UTC (a) 22 and (b) 23 October 2000 .

the easterly flow toward eastern Spain at low levels. At this time, enhanced organized convection is detected along the eastern Spanish coast and within the easterly cloud bands over the sea. An extensive mesoscale convective system with nearly a circular shape is detected over Valencia at this time. On the other hand, the frontal system identified northwest of the Iberian Peninsula in Fig. 5a has not advanced into inland Spain and at 23/12 has drastically weakened, resulting in the thin, cloudy filament that is crossing the northwest Iberian Peninsula.

As a result of the convection identified in Fig. 5, torrential precipitation was registered over Catalonia and Valencia (Fig. 6). On 21 October (not included in Fig. 6), isolated nuclei of significant precipitation (we will refer to significant rainfall as amounts $>10 \mathrm{~mm} / 24 \mathrm{~h}$ ) were registered over Catalonia, Valencia and Murcia, and a small nucleus with values

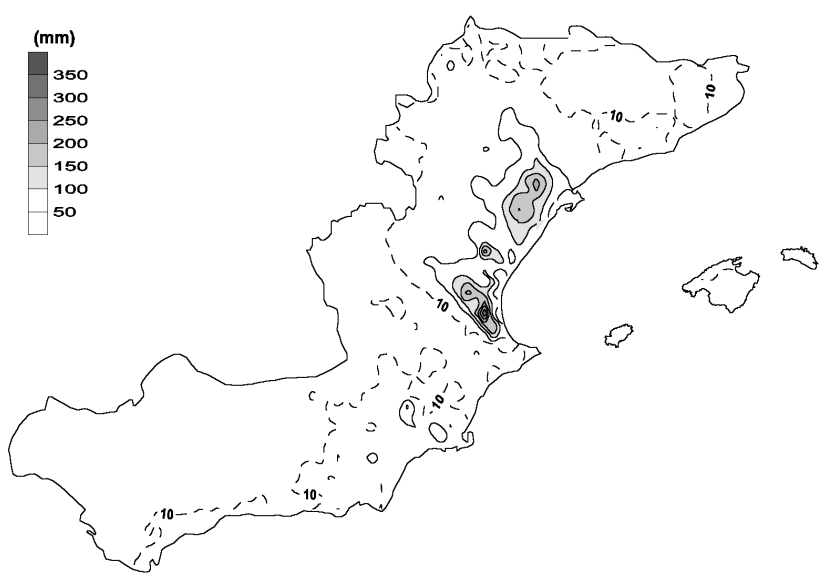

(a)

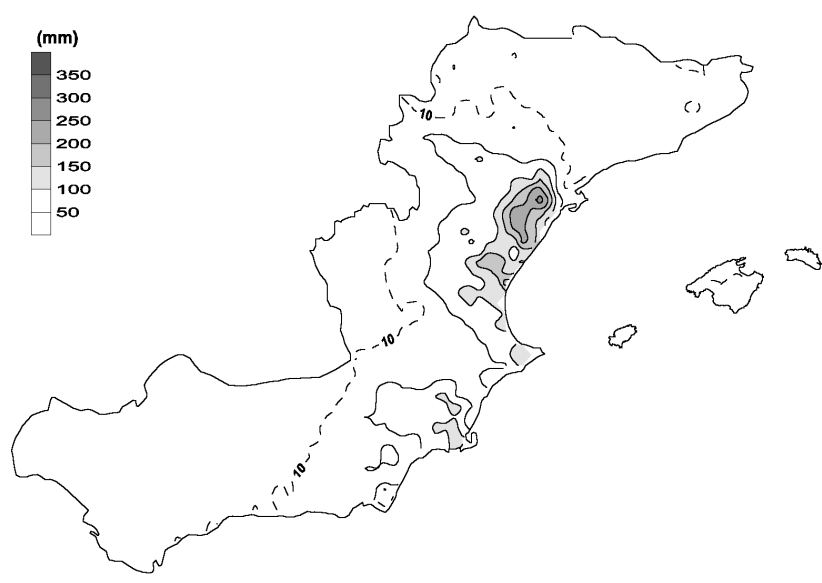

(b)

Fig. 6. Analysis of the accumulated precipitation $(\mathrm{mm})$ from 07:00 UTC to 07:00 UTC the next day on: (a) 22 and (b) 23 October 2000. The stations and the covered area is the same as in Fig. 2.

higher than $150 \mathrm{~mm}$ was detected south of Catalonia. Significant precipitation occurred on 22 October over a widespread area covering the Catalonia, Valencia and Murcia regions (Fig. 6a). The largest amounts were registered along coastal areas of south Catalonia and Valencia, with nuclei of $200 \mathrm{~mm}$ and even $300 \mathrm{~mm}$ near Valencia city. The precipitation registered on 23 October concentrated near about the same coastal band as on 22 (Fig. 6b). On this day however, no significant precipitation was registered over north and east of Catalonia, but more than $250 \mathrm{~mm}$ were recorded in some rain-gages to the south. In addition, amounts higher than $200 \mathrm{~mm}$ were also detected over Valencia. On the following day (24 October, not shown), a small nucleus achieving $200 \mathrm{~mm}$ was registered in northern Valencia, surrounded by a small area of significant precipitation. Note, despite that important convective activity could be inferred from the satellite imagery over the Balearic Islands, no important amounts were regis- 
tered over land for the whole period. The well-known uncertainties which affect the precipitation amounts collected by rain-gages could explain these differences over the area. Referring to the rainfall over the sea, no radar images are available for most of 22 and 23 October from Valencia, due to technical problems occurred during those days in the radar station. Even so, the images from the radar in Murcia at 23/11 (not shown) reveal the presence of deep convective developments off the Valencian coast, achieving a $10-12 \mathrm{~km}$ altitude, as well as a developing band to the south, which confirms the occurrence of intense precipitation over the sea.

Thus, available observations show the usual scenario for heavy rainfall events in the western Mediterranean, and broadly confirm the mechanisms included in the conceptual model discussed in Sect. 1. Nevertheless, to achieve a further understanding, the factors or dynamical processes leading to the 4-day lasting cutoff low aloft and the continuous persistent low-level easterly warm and moist flow must be determined. Diagnosis of the low-level situation, as well as numerical investigation of several upper-level synoptic-scale scenarios, form the basis of the following sections, in order to gain insight on the mechanisms and particular aspects leading to the torrential precipitation event. Furthermore, the sensitivity of the numerical model, a valuable tool for forecasters, to those factors responsible for the stagnancy of the system will also be investigated.

\section{Control simulation}

\subsection{Model configuration and control experiment description}

Several numerical experiments were performed using the fifth generation of the Pennsylvania State UniversityNational Center for Atmospheric Research Mesoscale Model (MM5v3, Dudhia, 1993; Grell et al., 1995). The MM5v3 is a full non-hydrostatic model formulated using the terrainfollowing $\sigma$-coordinate system in the vertical. The multiplenest capability of the model has been used in order to capture both the synoptic-scale evolution and the mesoscale features of the episode with manageable computational cost. Three domains under a Lambert conformal map projection were used to cover the wide range of scales of interest in this study. The coarse $82 \times 102$ grid point domain, with a $90 \mathrm{~km}$ resolution, measures $7290 \mathrm{~km} \times 9090 \mathrm{~km}$ and covers Europe, North Africa and most of the north Atlantic Ocean (see Fig. 3). This domain is used to reproduce the large-scale aspects of the event. The second domain has a $30 \mathrm{~km}$ resolution and $91 \times 91$ grid points. It covers the western Mediterranean basin and an additional area of north Africa (see Fig. 9), in order to capture consistently the effects of the cutoff low identified in Sect. 2. A two-way nesting strategy is used by this domain to interact with both the coarse and fine domains. The fine $109 \times 109$ grid domain is centered over the Balearic Channel and covers the eastern Iberian Peninsula and the Balearic Islands (see Fig. 7). The domain measures $1080 \mathrm{~km} \times 1080 \mathrm{~km}$ with a
$10 \mathrm{~km}$ horizontal grid spacing. The time steps used are $240 \mathrm{~s}$, $80 \mathrm{~s}$ and about $27 \mathrm{~s}$, respectively. Initial and boundary conditions for the coarse domain are constructed from the Global analyses of the National Center for Environmental Prediction (NCEP), available at 00:00 UTC and 12:00 UTC, which are reanalyzed at the model resolution using surface and upperair observations.

Referring to the time span covered by the experiments, since the largest daily rainfall amounts occurred during 22 and 23 October (Fig. 6) and the upper level cutoff formed during 21 October (Fig. 3), a 90-h long simulation was performed for domain 1: from 20/12 to 24/06. Domains 2 and 3 started at $22 / 00$ and extended $54 \mathrm{~h}$, until $24 / 06$. Since the simulated time interval covers the scenario previous to the cutoff low formation and the days with the most intense rainfall, this configuration allows for the study of possible influences of modifications to the cutoff pre-scenario, on the precipitation or any other mesoscale feature of interest captured by the model.

The MM5v3 model includes different physical parameterizations. For the present study, the Kain and Fritsch (1990) convective parameterization scheme was used for domains 1, 2 and 3. At the resolution of domains 2 and 3, coexistence of explicit and parameterized convection is shown to offer the optimal representation of the convective developments in numerical models (Kain and Fritsch, 1997). Resolved-scale moist processes follow the rich microphysics scheme of Tao and Simpson (1993), based on the Lin et al. (1983) mixed-phase scheme. It includes equations for the prediction of rain and cloud water, graupel and ice concentration number. The parameterization chosen to represent the planetary boundary layer subgrid processes is a modified version of the Hong and Pan (1996) scheme. It includes an implicit vertical diffusion scheme, assuming a k-profile, which uses a counter-gradient equation. Sea level temperatures remain constant during the simulation and are taken from the NCEP weekly analysis. A sophisticated radiation scheme is used. It accounts for long-wave and shortwave interactions with the model explicit clouds, clear air and precipitation (Benjamin, 1983).

\subsection{Model validation}

The numerical study intended in the next section requires obtaining a control run which reproduces, to some extent, the observed meteorological aspects of the event. The model simulation must reproduce the observations to accept a run as a useful control run, keeping in mind the model's intrinsic limitations and the extent of the further numerical study. In this case, the model reproduces accurately the synoptic evolution as analyzed in the NCEP fields at all tropospheric levels. In particular, the upper-level cutoff and the LLJ over the western Mediterranean are well captured. In addition, the model simulates the environment and the convective activity which produced the torrential rainfall with remarkably accuracy. Notable precipitation amounts are simulated along the Spanish Mediterranean coastal lands (Fig. 7). As ex- 


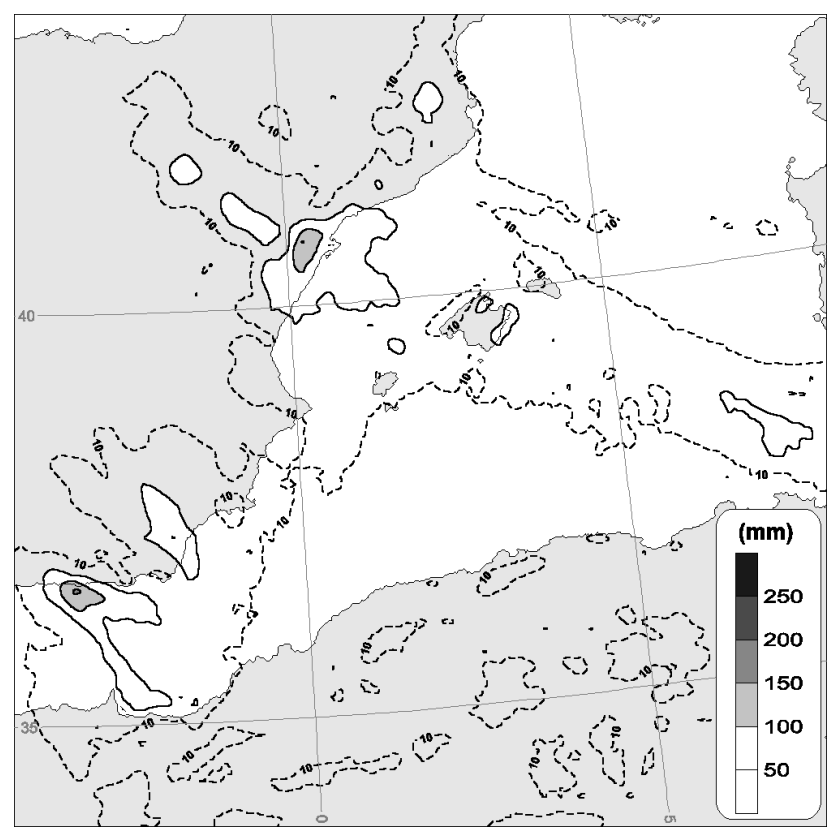

(a)

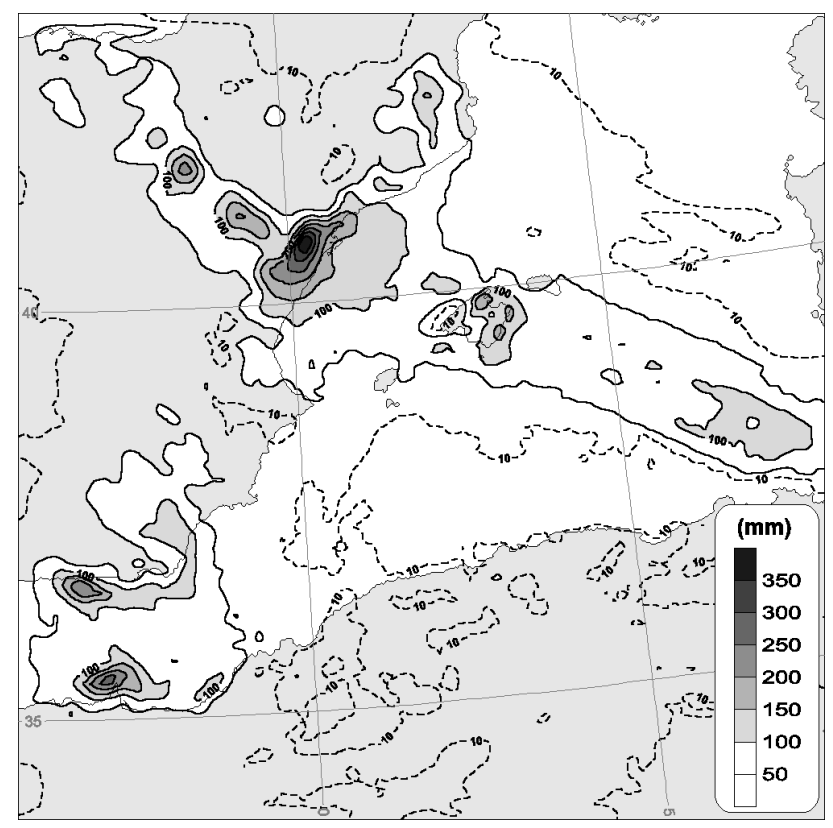

(c)

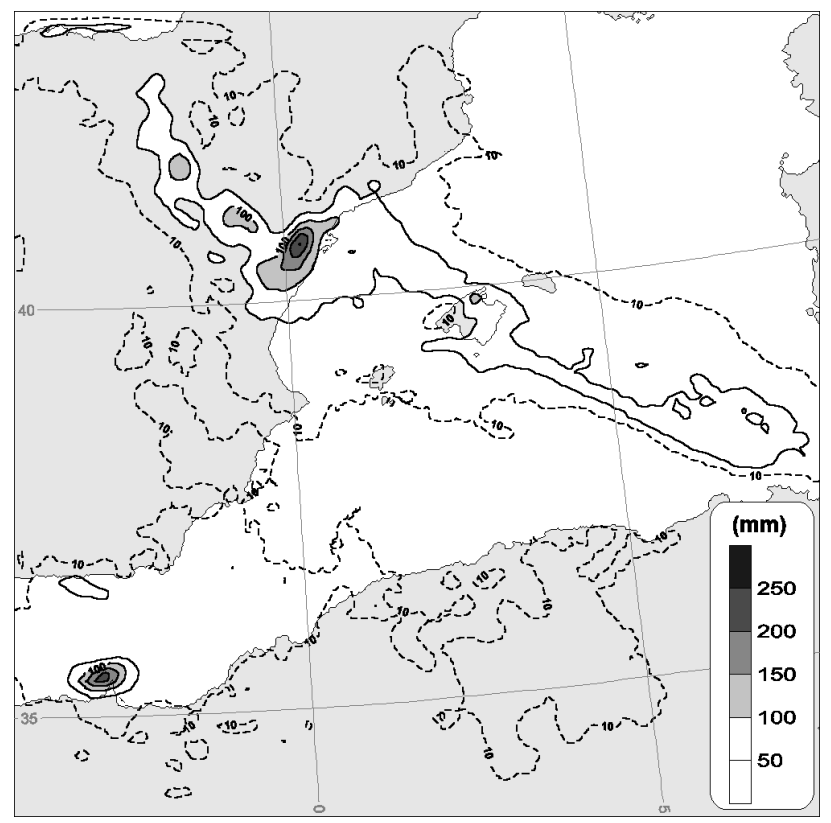

(b)

Fig. 7. Model simulated accumulated precipitation (mm, domain 3) from 06:00 UTC to 06:00 UTC the next day on: (a) 22 and (b) 23 October 2000. (c) Shows the total accumulated precipitation $(\mathrm{mm})$ in the control simulation for 22 and 23 October (sum of $a$ and $b$ ). Note the change of precipitation scale between the first two panels and $c$.

pected, the precise location and intensity of the heavy precipitation nuclei observed in Fig. 6 are not reproduced exactly in the simulation. However, the simulated precipitation distribution resembles the observed precipitation distribution for 22 October (Fig. 7a), and significant precipitation is simulated over Catalonia, north of Valencia and Murcia. In addition, heavy rainfall is simulated over a band along the coast of Valencia, with amounts in excess of $100 \mathrm{~mm}$, comparing well with the observed pattern (Fig. 6a). For 23 October, similar agreement is observed between simulation and observations (Figs. $7 \mathrm{~b}$ and $6 \mathrm{~b}$ ), with more than $250 \mathrm{~mm}$ of simulated and observed rainfall south of Catalonia. The model simulates correctly the precipitation distribution, restricting the most intense precipitation over land, to the coastal areas.

Note that there is no signal in the observations (Fig. 6b) of the heavy precipitation simulated over Mallorca on 23 October. Since any operational radar covers the Balearic Islands area, it cannot be determined whether this important precipi- 

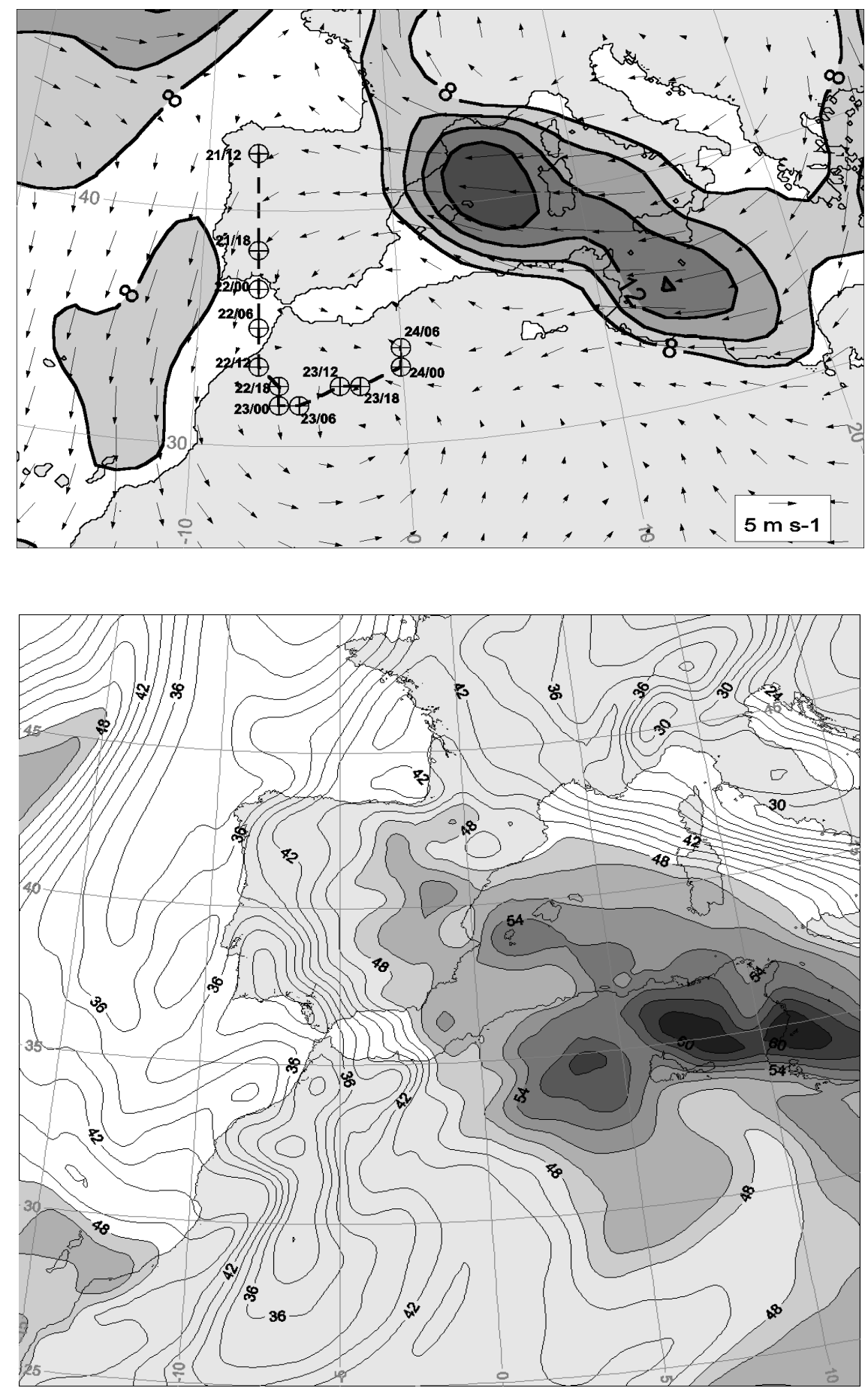

Fig. 8. Position of the cutoff low center at $300 \mathrm{hPa}$ (circled crosses), from 12:00 UTC 21 to 06:00 UTC, 24 October 2000 as simulated in the control run (zoom on domain 1). Vector field and shaded contours show the 48-h averaged wind and wind speed $(\mathrm{m} / \mathrm{s})$ greater than $8 \mathrm{~m} / \mathrm{s}$ at $1000 \mathrm{hPa}$ from 00:00 UTC 22 to 00:00 UTC, 24 October 2000.
Fig. 9. Distribution on domain 2 of equivalent potential temperature $\left({ }^{\circ} \mathrm{C}\right)$ at $1000 \mathrm{hPa}$ on 12:00 UTC 22 October 2000, with shading for values greater than $48^{\circ} \mathrm{C}$. tation band actually existed northwards or southwards of the Balearics, though it appears to be supported by the satellite image shown in Fig. 5b.

Then, taking into account that the present investigation is not focused on the individual convective cells but on the synoptic and mesoscale processes leading to the environment in which the heavy precipitation was produced, the control run appears to be reproducing such processes with enough accuracy to be considered for further diagnosis and numerical experimentation.

\subsection{Diagnosis of large-scale ingredients}

The main synoptic-scale features which characterized the event have been previously presented in the analyses shown in Figs. 3 and 4. The control simulation reproduces the cutoff low development, as well as the persistent easterly low-level flow. Figure 8 summarizes the evolution of these synopticscale structures. The cutoff low at the upper levels formed about 21/12 and advanced southwards, remaining nearly stationary south of the Iberian Peninsula on the days 22 and 23. 


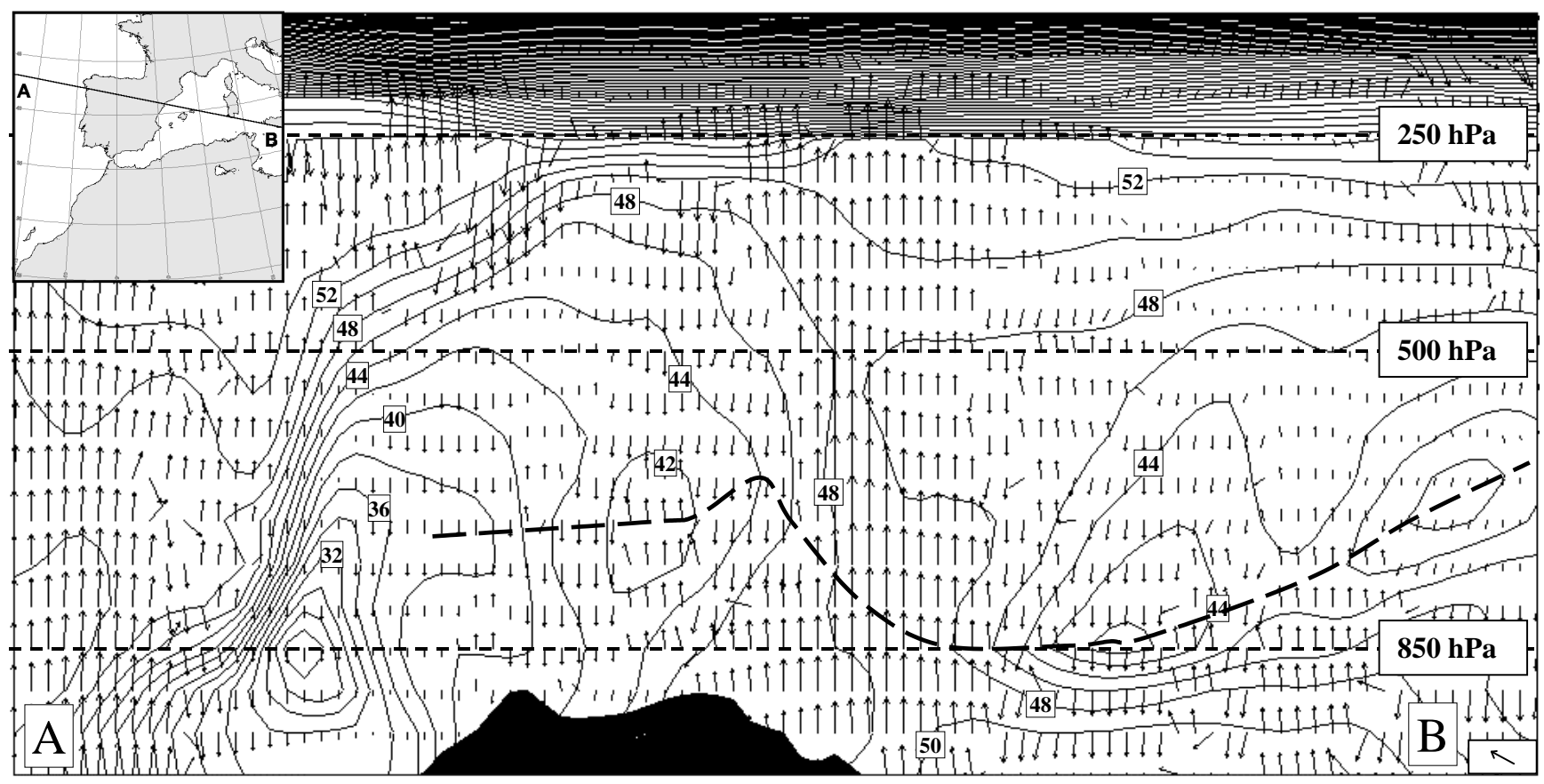

Fig. 10. Vertical cross section of domain 2 showing equivalent potential temperature $\left({ }^{\circ} \mathrm{C}\right)$ and wind (m/s) on 12:00 UTC, 22 October 2000 . Strong dashed line bounds the region with greater convective instability. The top left map shows the vertical section position. The wind scale is indicated by the bottom right corner vector with components $13 \mathrm{~m} / \mathrm{s}$ in the horizontal and $0.07 \mathrm{~m} / \mathrm{s}$ in the vertical.

Meanwhile, persistent low-level easterly flow was impinging toward the Spanish Mediterranean coast. A low level jet (LLJ) is clearly identified over the sea, from the Libyan coast to eastern Spain, with 48-h averaged $1000 \mathrm{hPa}$ winds higher than $12 \mathrm{~m} / \mathrm{s}$. The averaged wind field also depicts a cyclonic circulation over northwestern Africa associated with the cutoff low. This persistent low-level flow over the Mediterranean Sea from a region of warm air generates a warm and moist tongue already identifiable during the first hours of 22 October (Fig. 9). High values of equivalent potential temperature (EPT) are found at low levels over the western Mediterranean. This air mass was not present over the area on 20 October and first hours of 21 October, but started forming when the long fetch of easterly flow was established at low levels. The presence of warm and moist air at low levels generated convective instability over the area. Figure 10 shows a wide area over the sea showing convectively unstable profiles, with remarkable negative vertical EPT gradients around $850 \mathrm{hPa}$. At this time, weak vertical EPT gradients are found over the Spanish Mediterranean coast due to the already developed convective overturning, seen in Fig. 10 as an intense deep coastal updraft.

An evaluation of convective available potential energy (CAPE; Weisman and Klemp, 1986) is done using the expression:

$C A P E=-R_{d} \int_{p_{f}}^{p_{n}} \frac{T_{p}-T_{a}}{p} d p$,

where $R_{d}$ is the gas constant for dry air, $T_{p}$ represents parcel temperatures and $T_{a}$ ambient environmental temperatures.
Parcel temperatures are calculated by performing pseudoadiabatic ascents from the level of free convection $\left(p_{f}\right)$ to the level of neutral buoyancy $\left(p_{n}\right)$. Figure 11 shows an averaged CAPE distribution which reveals that favorable conditions for convective developments were found over the south and west of the western Mediterranean. Values up to $750 \mathrm{~J} / \mathrm{kg}$ were present off the Valencian coast.

In addition to the convective and latent instabilities, which are both already favored by moist air at low levels, high water vapor content is required throughout a deep tropospheric column, in order to support high precipitation efficiency by the convective systems and, therefore, torrential rainfall amounts. A useful measure of the available water vapor for condensation in a vertical column is the precipitable water $(\mathrm{PW})$ field, calculated as:

$P W=g^{-1} \int_{p_{\text {top }}}^{p_{0}} q d p$,

where $q$ is the specific humidity and $g$ the gravity. The calculation of PW is extended from the surface $\left(p_{0}=1000 \mathrm{hPa}\right)$ to the model top layer $\left(p_{t o p}=100 \mathrm{hPa}\right.$ ), though the main contribution is obtained from below $600 \mathrm{hPa}$ layer. Figure 12 shows the distribution of $\mathrm{PW}$ at 23/00. A similar structure to that obtained for the EPT field is found: high values on a tongue-shaped structure over the southern western Mediterranean, with amounts achieving $35 \mathrm{~mm}$ over the eastern Spanish coast. The high values of PW result from the transport of water vapor toward the area from two different origins. At mid-levels, humid air from the broken Atlantic 


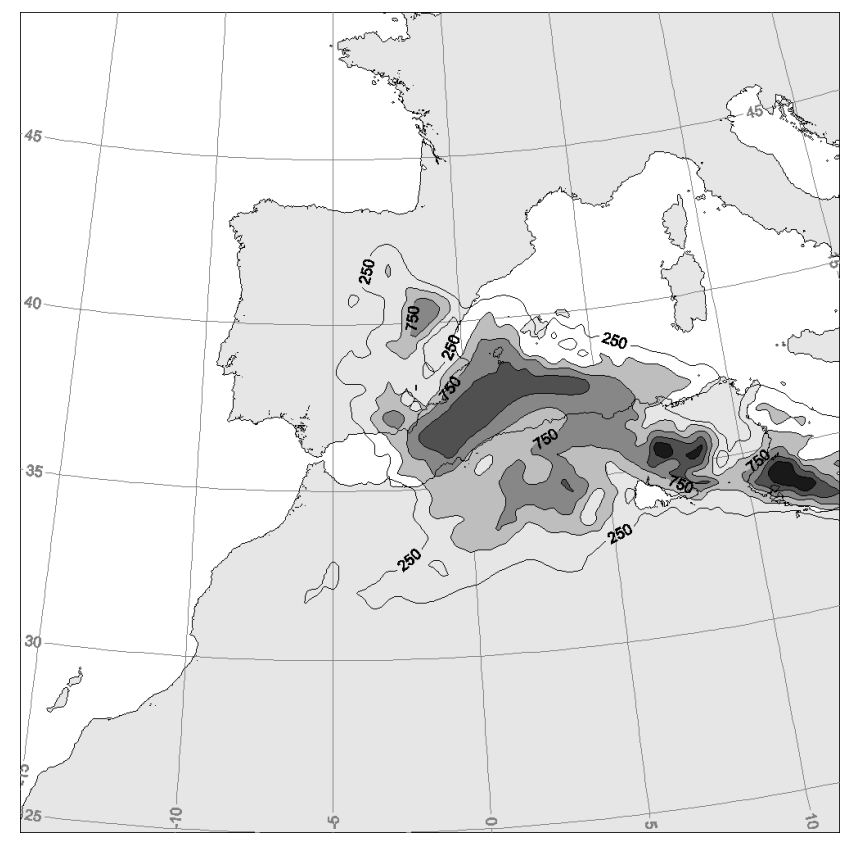

Fig. 11. The 24-h averaged CAPE distribution $(\mathrm{J} / \mathrm{kg})$ calculated for the sea level parcels of domain 2 from 12:00 UTC 22 to 12:00 UTC, 23 October 2000.

frontal system, described in Sect. 2, is transported progressively northwards by the cutoff low associated flow. At low levels, the water vapor supply is led by the persistent easterly LLJ, which produces water vapor convergence at its exit region, over the eastern Spanish coast, and also induces intense evaporation from the sea. Figure 12 also shows the 24-h averaged distribution of water vapor flux convergence and the latent heat flux from the sea. The water flux convergence is defined as:

$W F C=-g^{-1} \int_{p_{f}}^{1000} \nabla \cdot(\boldsymbol{U} q) d p$.

In our calculations, $p_{f}$ is taken as $700 \mathrm{hPa}$, therefore, including the water supply at the lower troposphere. Figure 12 confirms that moderate evaporation is present during the period, especially to the east and southeast of the western Mediterranean basin. The entrance zone of the LLJ is located over this area, so the water vapor supplied by evaporation is transported efficiently westwards.

Thus, the environmental thermodynamic ingredients required for sustaining intense precipitation are present in this event: high latent and convective instabilities to be released, and notable amounts of PW to feed the convective systems ahead of the LLJ, necessary to maintain the precipitation efficiency. However, a subsynoptic lifting mechanism is necessary for the convective systems to develop and this mechanism is favored where the large-scale vertical motion is promoted. For this event, dynamic forcing for upward motion is weak at the synoptic scale over the region of interest, because it lays between the cutoff low to the south and the northern belt of the westerlies. In fact, calculation of the forcing term of the $\omega$-equation using the $\boldsymbol{Q}$-vector formulation (-2 $\nabla \cdot \boldsymbol{Q}$, Holton, 1992) shows a weak signature at both upper and lower levels over the western Mediterranean (Fig. 13). At the upper levels, important forcing for upward and downward motion is associated with the cutoff cyclone circulation over north Africa, but weak values are attained over the western Mediterranean Sea. A similar structure is found at low levels, with moderate positive and negative values over north Africa, but very weak upward quasi-geostrophic forcing over the eastern Iberian Peninsula and the Balearic Islands area. Such scenarios with weak synoptic forcing for upward motion have been observed previously in severe weather events in the western Mediterranean (Romero et al., 2000), thereby emphasizing that the mesoscale features are the dominant factors in the development and evolution of convection (Stensrud and Fritsch, 1993). Despite the fact that no clear signal of large-scale dynamical contribution to upward motion is found, note that opposition to subsynoptic upward motion mechanisms is also not found at the synoptic scale. Mechanisms such as the orographic upslope flow, the convergence zone ahead of the LLJ, or the convergences produced by the different sea-land drag appear as possible subsynoptic lifting mechanisms in this episode. The precise identification of the lifting mechanisms responsible for the triggering of the individual convective cells is a complicate issue in convection studies (Rockwood and Maddox, 1988).

\section{Sensitivity experiments}

Once the most relevant synoptic-scale ingredients for the development of the episode have been diagnosed, the investigation of its origin and a quantification of its effect is addressed. Furthermore, the role of the orography on the episode, as a direct lifting mechanism of the low-level parcels or through the induced modification of the low-tropospheric wind field, is also analyzed.

A first evaluation of the role of the cutoff low present at the upper levels during the entire episode is done. To this end, the PV inversion technique of Davis and Emanuel (1991) is used. The method consists of resolving the geopotential $\phi$ and the streamfunction $\psi$ from a system formed by an approximate form of the Ertel PV definition, i.e. $q=\frac{1}{\rho} \boldsymbol{\eta} \cdot \nabla \theta$, where $\rho$ is the density, $\boldsymbol{\eta}$ is the absolute vorticity and $\theta$ is the potential temperature, and the Charney (1955) nonlinear balance condition:

$$
\begin{gathered}
q=\frac{g \kappa \pi}{p}\left[\left(f+m^{2} \nabla^{2} \psi\right) \frac{\partial^{2} \phi}{\partial \pi^{2}}-m^{2}\right. \\
\left.\cdot\left(\frac{\partial^{2} \psi}{\partial x \partial \pi} \frac{\partial^{2} \phi}{\partial x \partial \pi}+\frac{\partial^{2} \psi}{\partial y \partial \pi} \frac{\partial^{2} \phi}{\partial y \partial \pi}\right)\right] \\
\nabla^{2} \phi=\nabla \cdot f \nabla \psi+2 m^{2}\left[\frac{\partial^{2} \psi}{\partial x^{2}} \frac{\partial^{2} \psi}{\partial y^{2}}-\left(\frac{\partial^{2} \psi}{\partial x \partial y}\right)^{2}\right],
\end{gathered}
$$



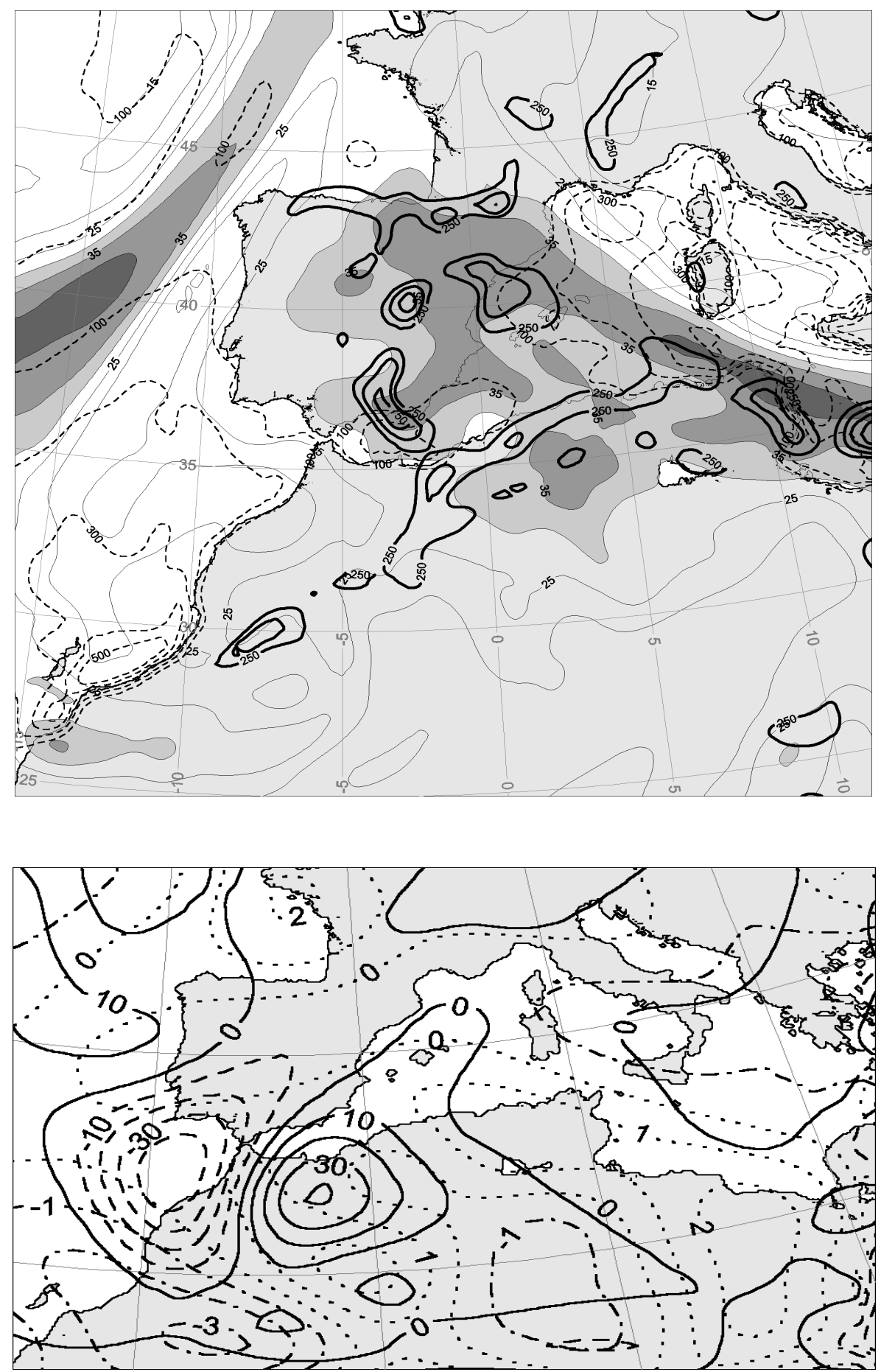

Fig. 12. Precipitable water (mm, thin solid line, with shaded areas indicating values greater than $30 \mathrm{~mm}$ ) on 00:00 UTC, 23 October 2000, and 24-h averaged water vapor flux convergence integrated from 700 to $1000 \mathrm{hPa}$ $\left(\mathrm{gm}^{-2} \mathrm{~s}^{-1}\right.$, strong solid line) greater than $200 \mathrm{gm}^{-2} \mathrm{~s}^{-1}$; and 24-h averaged latent heat flux $\left(\mathrm{Wm}^{-2}\right.$, dashed line) from 12:00 UTC 22 to 12:00 UTC, 23 October 2000 shown for domain 2.

Fig. 13. Forcing term $(-2 \nabla \cdot \boldsymbol{Q})$ of the quasi-geostrophic $\omega$-equation $\left(10^{-18} \mathrm{~m} / \mathrm{kgs}\right)$ on 00:00 UTC, $23 \mathrm{Oc}$ tober 2000 for domain 1 (zoom), at $300 \mathrm{hPa}$ (solid and dashed lines indicate positive and negative values, respectively), and 700 to $1000 \mathrm{hPa}$ averaged value (dotted and dash-dotted lines indicate positive and negative values, respectively). Note the different contour interval between upper and lower levels fields.

with $g$ as the gravity, $\kappa=R_{d} / C_{p}$, the vertical coordinate $\pi$ is the Exner function $C_{p}\left(p / p_{0}\right)^{\kappa}, p$ is the pressure, $f$ is the Coriolis parameter, and $m$ denotes the map-scale factor.

Then, from an instantaneous distribution of PV and a boundary conditions set, the three-dimensional distributions of $\phi$ and $\psi$ are obtained. Dirichlet upper and bottom boundary conditions are used, following $\partial_{\pi} \Phi=-\theta$. As shown by Davis and Emanuel (1991), the balance fields resulting from the inversion process are notably accurate, even at large Rossby numbers, due to the accuracy of the nonlinear balance condition used. The three-dimensional temperature field is obtained by using the hydrostatic assumption, whereas the relative humidity is left unmodified in this process. Consequently, a modification in the temperature field using the PV inversion process will result in a variation in the specific humidity, but will not affect the original saturation properties.

Using this method, the dynamical structures of an instan- 


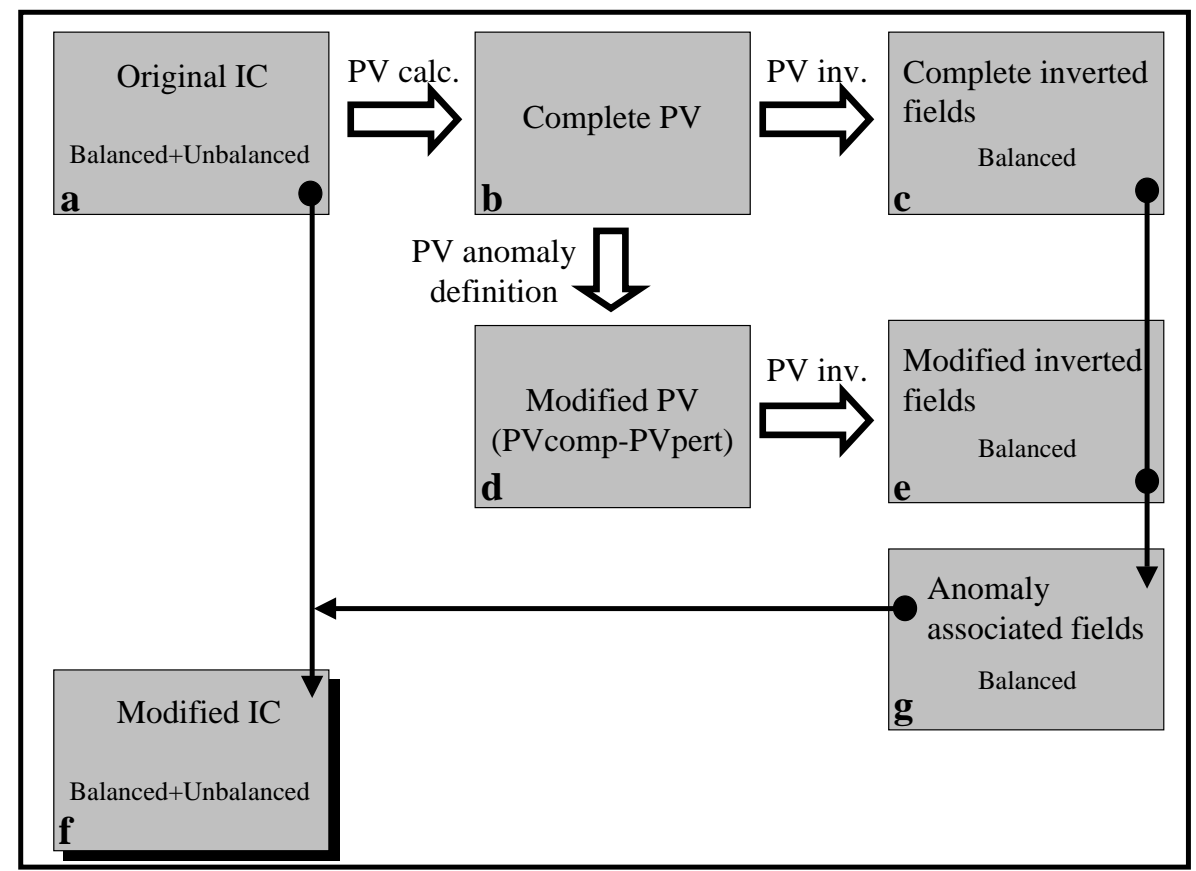

Fig. 14. Diagram showing the process of initial conditions modification using the PV inversion technique. Labels indicate the references to the process included in the text. taneous atmospheric state can be modified without introducing spurious mass and wind fields imbalances. Referring to applications to numerical experimentation, this technique offers the interesting possibility of analyzing quantitatively the effects of dynamical structures of the flow on any model output. The coherent modification of these dynamical structures in the initial or boundary conditions (box a, in Fig. 14), based on its PV counterpart (box b), allows for the analysis of its effect on the numerical simulation, by a simple comparison with the original run. Particularly for the present study, the identification of the PV structure associated with the cutoff low precursor trough has been done, allowing, for instance, to diminish its intensity, perform the inversion process and obtain the geopotential and streamfunction fields (e) corresponding to the modified PV field (d). The geopotential and streamfunction perturbations ( $g$ ) associated with the PV anomaly are obtained by substracting the inverted fields of the modified PV from the inverted fields of the complete PV distribution. Then, the modified initial conditions (f) are obtained by substracting from the original fields (a) those associated with the anomaly $(\mathrm{g})$. Following this methodology, only the part of the original initial conditions associated with the PV anomaly is subtracted, avoiding the modifications to the original fields produced by the inversion process itself. Note that only the balanced part of the initial conditions is modified following this line of proceeding. The boundary conditions used to solve the system of equations for the weakened-cutoff low are taken as the original unperturbed fields, thereby making it convenient to perform the modifications of the PV field at areas far from the boundaries. Figure 15 shows the PV, geopotential height and temperature fields at $300 \mathrm{hPa}$ of the original and weakened precursor trough. The eliminated portion from the trough representing positive PV anomaly has values up to $2.5 \mathrm{PVU}$ at $300 \mathrm{hPa}$ and extends from $450 \mathrm{hPa}$ upwards. The effect of weakening this $\mathrm{PV}$ anomaly is to diminish the trough intensity by reducing the vorticity field and to weaken the stability at the anomaly level by warming below and cooling above the perturbation.

A simulation using the modified fields at 20/12 as initial conditions is performed. This simulation also reproduces the cutoff low development aloft, but a dramatic change in the accumulated precipitation field with respect to the control run is obtained (Fig. 16). Highest amounts over land barely reach $30 \mathrm{~mm}$. This reveals an extremely high sensitivity of the precipitation amounts to the intensity of the upper level trough for this event. On the other hand, the upper-level cutoff low developed by this simulation is weaker and lays more to the west than in the control simulation. This results in a weakening and shifting of the dynamic forcing pattern for a sea level pressure fall in northern Africa and, consequently, the persistent easterly LLJ over the Mediterranean, observed in Fig. 8 for the control run, is not developed in this simulation (Fig. 17). Figure 18 shows a comparison of the sea level pressure pattern between the two simulations. It confirms that the original cutoff low forced a deepening of surface pressure over north Africa and south Mediterranean that, together with an intensification of the European anticyclone, produced the easterly LLJ over the western Mediterranean. As a result of the modification of the surface flow, averaged differences larger than $150 \mathrm{~W} \mathrm{~m}^{-2}$ in the latent heat flux from the Mediterranean are obtained (Fig. 18), though differences up to $250 \mathrm{~W} \mathrm{~m}^{-2}$ are found at some times. Thus, the influence of the upper-level cutoff low is not a direct upward motion forcing over the area of heavy precipitation, but indirect through the enhancement of the easterly flow over the western Mediterranean, producing the LLJ. 


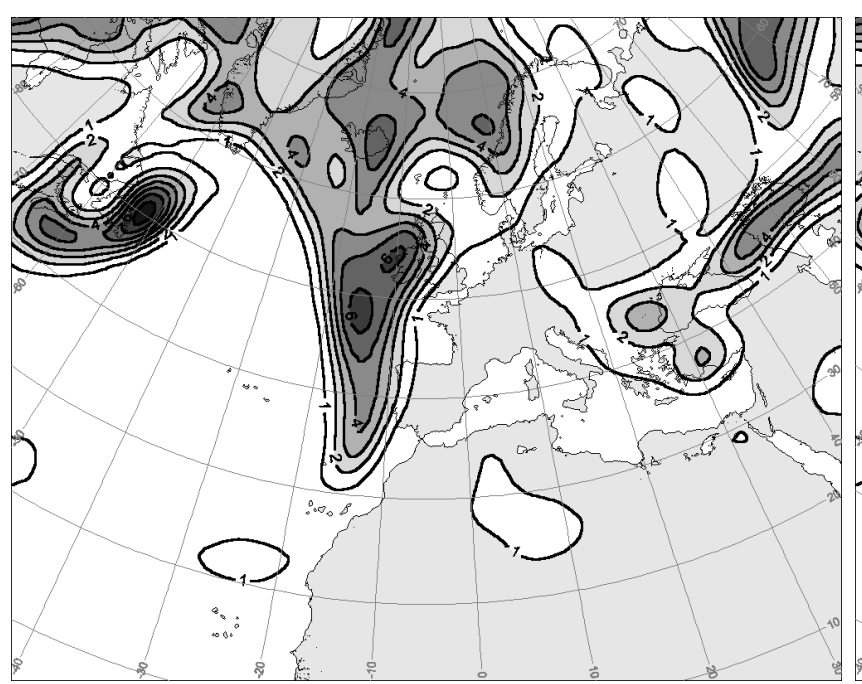

(a)

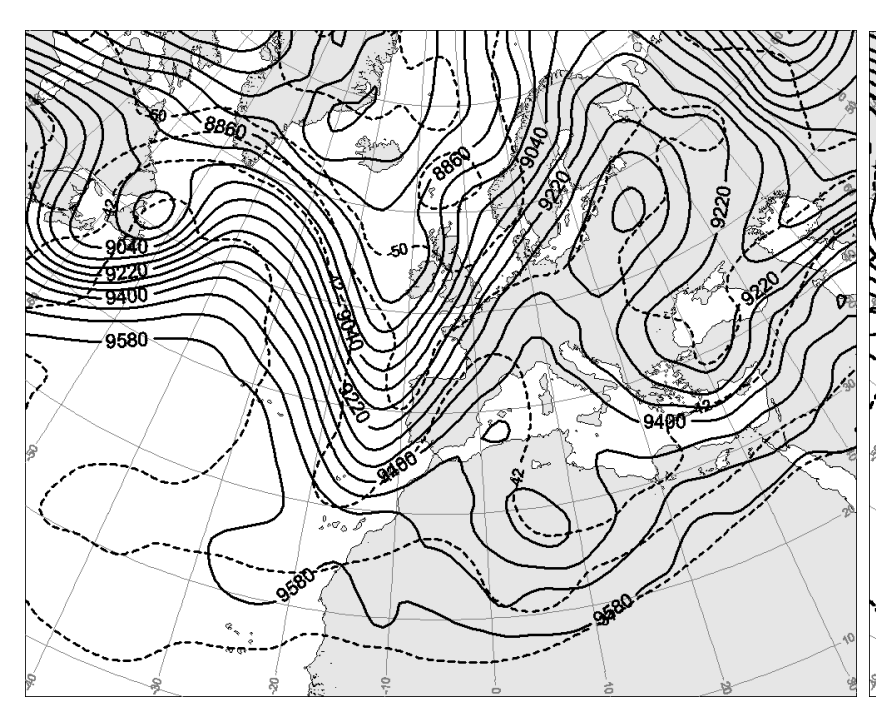

(c)

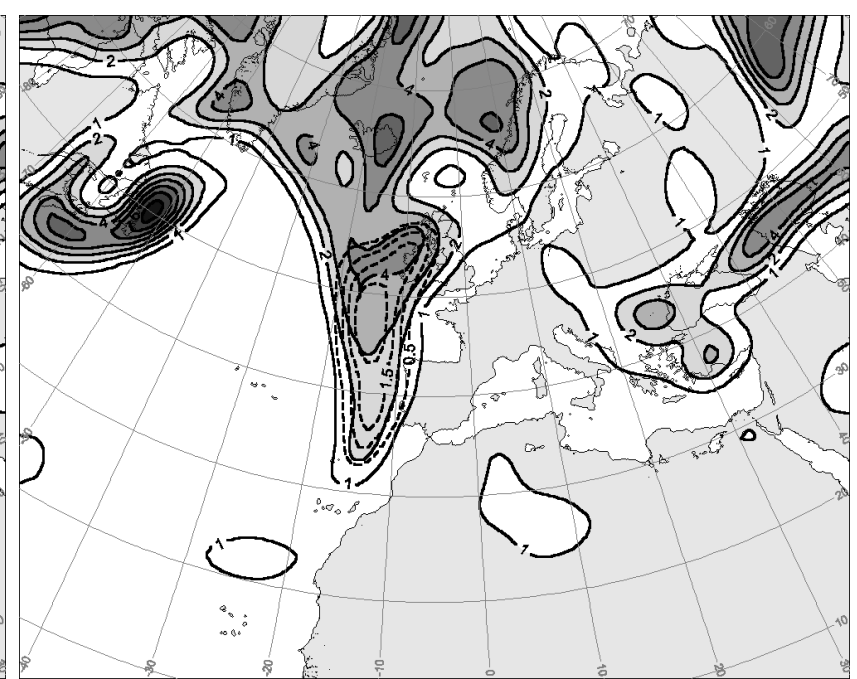

(b)

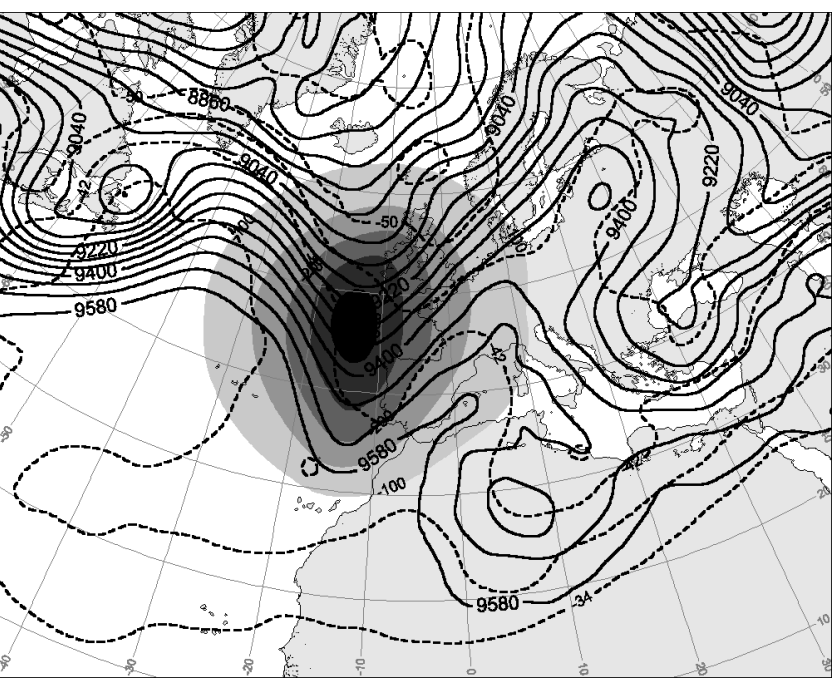

(d)

Fig. 15. Upper panels: Potential Vorticity (PVU) at $300 \mathrm{hPa}$ on 12:00 UTC, 20 October 2000 associated with the initial conditions of (a) control run and (b) weakened trough experiment (see text for details). Dashed line in b) depicts the eliminated PV anomaly at $300 \mathrm{hPa}$. Lower panels: Geopotential height (gpm, solid line) and temperature $\left({ }^{\circ} \mathrm{C}\right.$, dashed line) at $300 \mathrm{hPa}$ on 12:00 UTC, 20 October 2000 for (c) control run and (d) the weakened trough experiment. Shading in d) depicts the areas with difference of geopotential height between the control run and weakened experiment greater than $100 \mathrm{gpm}$ (contour interval is $50 \mathrm{gpm}$ ). All panels show the fields on domain 1 .

Likewise, the PW over the eastern Iberian Peninsula and Balearic Islands evolves in an absolutely different way in the weakened-trough simulation compared with the control run. Figure 19 shows the evolution of the PW integrated over an area covering the central part of eastern Spain, Balearic channel and the Balearic Islands. The PW in the control run increased significantly during 21 October due to the previously discussed low-level evaporation and mid-level moist air transport. In contrast, the PW in the weakened-trough simulation does not increase significantly during the entire episode due to the modification in the mid and low-level circulation, which drastically modifies the humid air transport toward the area and the evaporation from the Mediterranean (Fig. 18).

A quantification of the effect of the evaporation on the episode is done by performing a simulation identical to the control run, but with no latent heat flux from the sea (hereafter noLHF experiment). The aim of this experiment is to infer what portion of the humidity, which contributed to the heavy precipitation production, was already present 


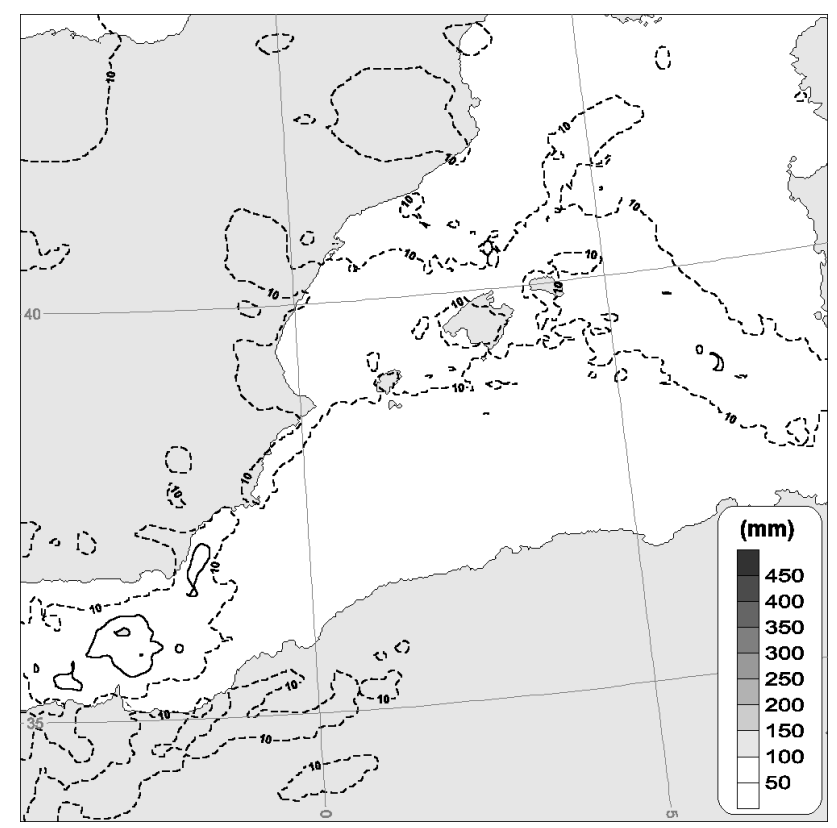

Fig. 16. As in Fig. 7c but for the weakened cutoff low precursor experiment.

in the atmosphere at 20/12 (i.e. in the model initial conditions; Romero et al., 1998b) and what portion was incorporated through evaporation from the sea during the days of the episode. In this simulation, the easterly LLJ over the western Mediterranean, an important transport agent of initially moist air toward eastern Spain, is similarly simulated, although no water vapor supply to the lower troposphere is allowed. The obtained precipitation is much weaker, with small nuclei achieving $50 \mathrm{~mm}$ over Valencia and Almeria, and with no significant precipitation over the sea. Moreover, most of this precipitation is concentrated in the first hours of 22 October, with similar rates as in the control run. A temporal evolution of the effects of the lack of evaporation on the tropospheric water content can be followed in Fig. 19. For this experiment, the PW in eastern Spain grows as the water vapor initially present in the domain advances toward the area. The humidity contributing to the increase is transported mainly at low levels and partially at mid-levels by the cutoff induced flow. From the first hours of 22 October, PW decreases due to the lack of an additional moisture supply and the sinking action of the clouds and precipitation. Giordani and Planton (2000) have shown that ageostrophic circulation and turbulent heat fluxes are in interregulation in the marine boundary layer, in order to minimize the atmospheric thermal wind imbalance. Thus, to better document the interaction between the LLJ and the surface heat fluxes, a finer analysis of the sea surface role on the episode has been conducted by performing two additional runs with the SST modified by \pm 3 and $\pm 5^{\circ} \mathrm{C}$ (not shown). The precipitation field on domain 3 of those experiments reveals that the higher the SST, the more intense the evaporation is, and the earlier and more strongly convective instability is built up and released over the sea as a consequence of the more intense warming and moistening of the low-level parcels. Even when the SST is decreased by $5^{\circ} \mathrm{C}$, precipitation amounts over eastern Spain are substantial (exceeding $300 \mathrm{~mm}$ ), but no significant amounts are obtained over the sea. This reflects that even when the evaporation from the sea is decreased, the low-level parcels are still moistened along its long westwards path, but not enough to overcome the convective inhibition given the weak dynamic forcing of this event. Then, the moist air achieves the complex topography of eastern Spain and important precipitation nuclei are still obtained over land.

In addition to the proper synoptic-scale environment for heavy precipitation, subsynoptic lifting mechanisms must have acted to provide the low-level parcels enough ascent to achieve its level of free convection over land. Orography is usually an important convection triggerer through upslope forced flow. The efficient interaction of the surface easterly winds with the orography of eastern Spain (Sistema Iberico, Pyrenees and local Valencian mountains) to trigger convective systems has been highlighted previously in former studies (i.e. Romero et al., 1998b; Homar et al., 1999). To investigate the precise effect of the orographic systems on this episode, a simulation identical to the control run but using flat topography is performed (hereafter non-orographic). Note that orographic effects are not strictly eliminated in the simulation, since both initial and boundary conditions, which only affect directly the coarser domain, also contain some orographic information. However, since the inner domain is started $36 \mathrm{~h}$ after the coarser one and it is sited far from the outermost boundaries, the orographic influence that is left on domain 3 is, in practice, unsignificant.

Figure 20 shows the accumulated precipitation obtained from the non-orographic experiment. When no orographic uplifting is present, the precipitation is substantially lower and the rainfall structures are not concentrated along the coastal lands, as in the control run (Fig. 7c). For this experiment, the $\mathrm{PW}$ evolution in the region is very similar to the control run (Fig. 19), and the amount of convective instability is also very similar in both runs. Thus, the orography did not appreciably modified the tropospheric thermodynamic environment, but it principally acted as a lifting and focusing mechanism along the coastal lands. When no orographic uplift is considered, other weaker triggering mechanisms emerge in the simulation, though much less efficient to trigger convection. Consequently, reduced amounts of precipitation, not focused over particular orographic structures are obtained in this experiment.

In summary, the numerical experiments performed in this section have revealed a capital influence of the upper-level cutoff low intensity and location for generating a surface low pressure system over north Africa, that induced and maintained the easterly LLJ over the western Mediterranean. The continuous supply by the LLJ of moisture rich maritime air, together with the intrusion of moist air at mid-levels from a previous Atlantic synoptic-scale disturbance, resulted in high values of precipitable water over eastern Spain. Apart from high humidity already present at the beginning of the simu- 

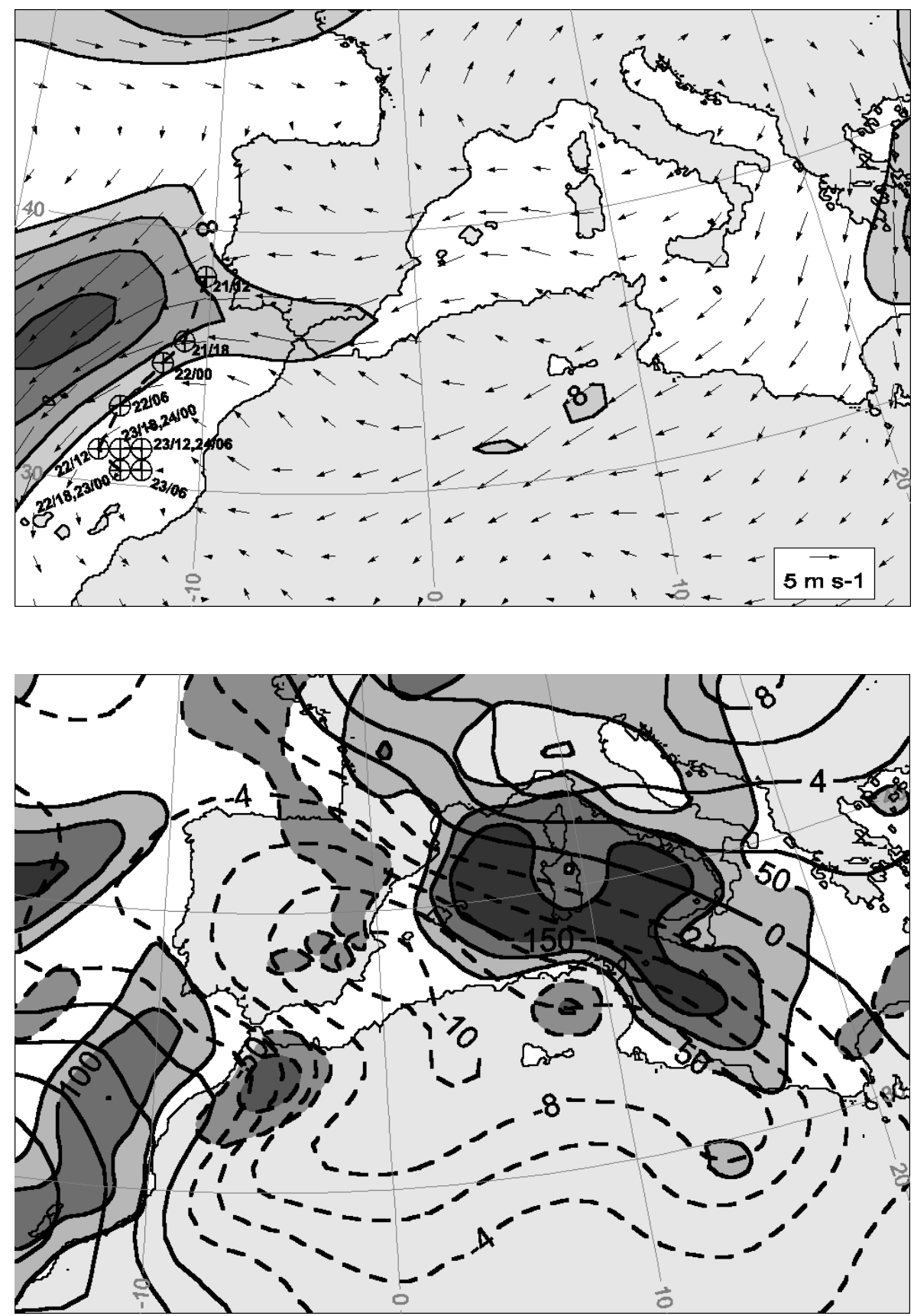

Fig. 17. As in Fig. 8 but for the weakened cutoff low precursor trough experiment. Note that the cutoff cyclone center locations of 22/18 and 23/00; 23/12 and $24 / 06 ; 23 / 18$ and $24 / 00$ coincide on the same model grid-points.

Fig. 18. Sea level pressure difference ( $\mathrm{hPa}$, solid and dashed lines indicate positive and negative values, respectively) between the control run and the weakened cutoff low precursor trough experiment on 12:00 UTC, 23 October 2000. Shaded contours indicate the latent heat flux difference $\left(\mathrm{W} \mathrm{m}^{-2}\right)$ greater than $50 \mathrm{~W} \mathrm{~m}^{-2}$ (contour interval is $50 \mathrm{~W} \mathrm{~m}^{-2}$ ) on 12:00 UTC, $23 \mathrm{Oc}$ tober 2000. A zoom over the western Mediterranean from domain 1 is done.

lations in the central Mediterranean, at the entrance zone of the later LLJ, a crucial effect can be attributed to evaporation for the continuous replenishment of water vapor in the lower troposphere. The coastal ranges of the eastern Iberian Peninsula have emerged as primary convection triggering agents, focusing the precipitation on complex terrain regions.

\section{Analysis of the upper levels stationarity}

The stationarity, intensity and location of the uppertropospheric cutoff low appear as the primary factors for producing the favorable conditions for heavy rainfall in the present case study. Moreover, the orography played a capital role in focusing the precipitation, and since it is reasonably well represented in the model at $10 \mathrm{~km}$ resolution, most of the forecast skills would be explained by the model's capability for reproducing the particular evolution of the upper levels flow pattern. As reflected in the NCEP analyses (Fig. 3), the cutoff low is almost circular and so, in terms of $\mathrm{PV}$, no notable self-advection occurred. In addition, a number of PV anomalies of different intensities configured the synoptic-scale situation in which the cutoff cyclone formed and remained nearly immobile. In this section, the role of the closest PV anomalies to the cutoff low precursor trough identified in the model initial conditions will be investigated. 


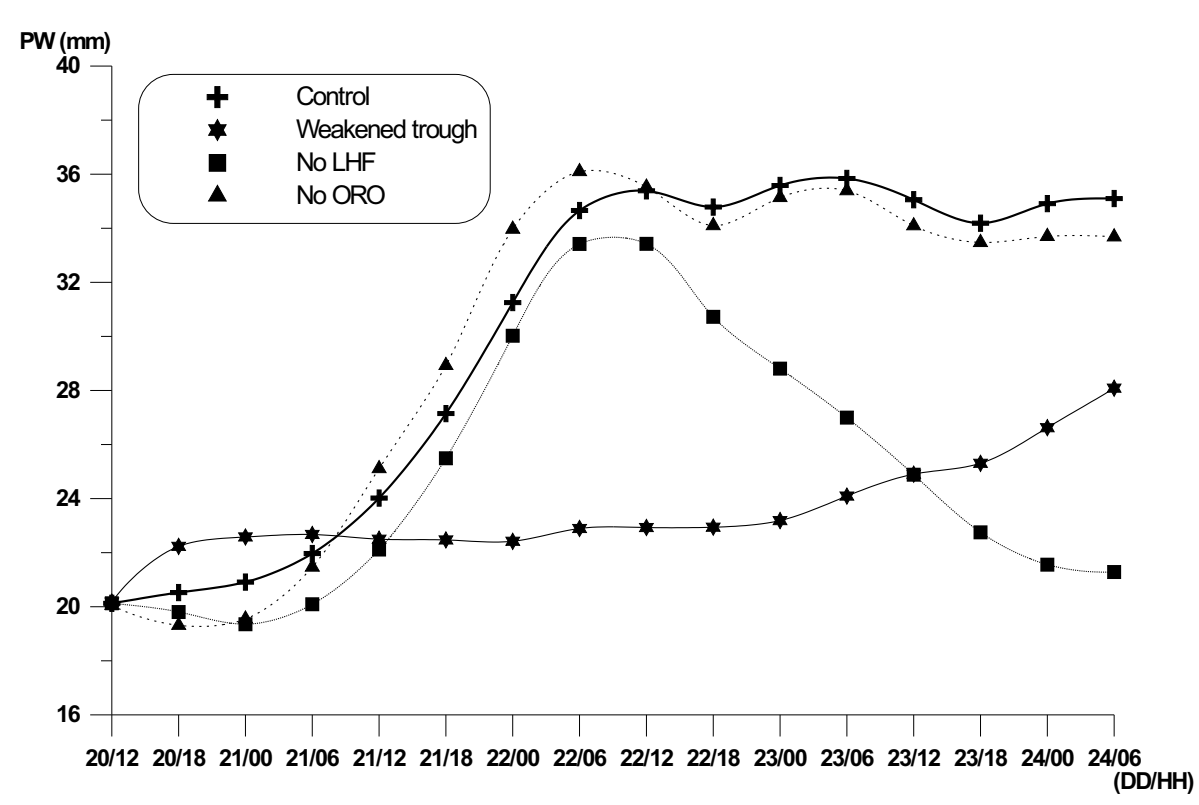

Fig. 19. Evolution of the precipitable water $(\mathrm{mm})$ horizontally integrated over eastern Spain for the control run (heavy solid line with crosses), the weakened cutoff low precursor trough experiment (solid line with stars), the experiment with no evaporation (solid line with squares) and the experiment with flat topography (doted line with triangles). Dates are given in the $\mathrm{DD} / \mathrm{HH}$ format referring to the HH:00 UTC hour of the DD day of October 2000.

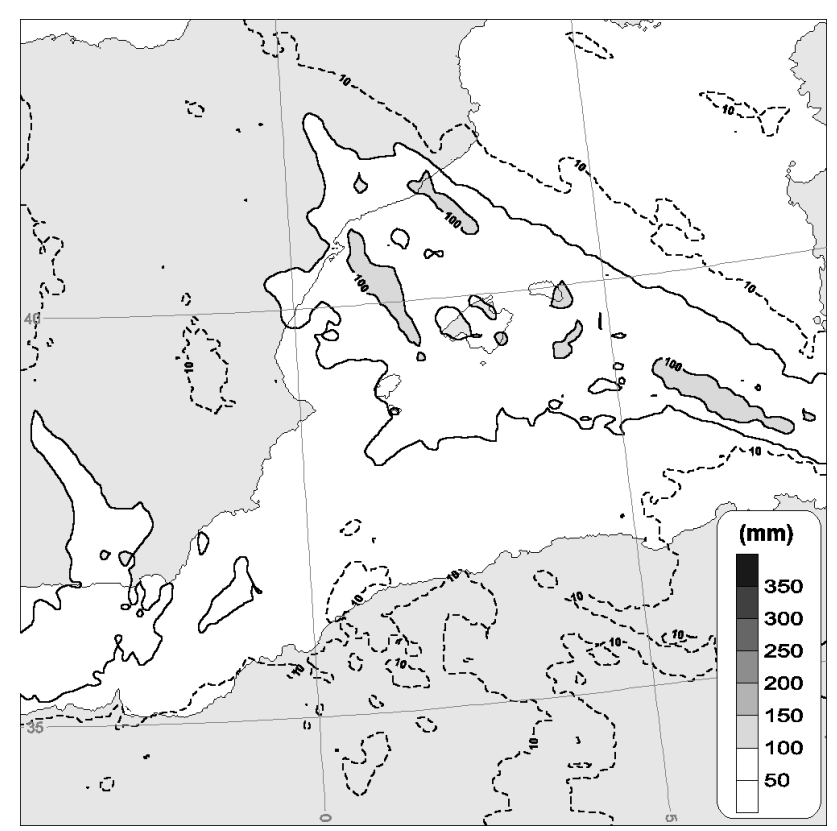

Fig. 20. As in Fig. 7c but for the non-orographic experiment.

Figure 21 shows the PV perturbation field at $300 \mathrm{hPa}$, calculated by substracting the PV isobaric horizontal mean from the PV field obtained from NCEP analysis at the initial model time, 21/12. Anomaly $A$ corresponds to the cutoff-precursor trough studied in Sect. 4, negative anomalies $B$ and $C$ correspond to the synoptic-scale highs located east and west of the aforementioned trough, respectively. Qualitatively, the anticyclonic circulation associated with $B$ works against the southwards stretching of anomaly $A$. Later, when the $A$ filament is cutoff from the high-latitude PV reservoir, anomaly $B$ opposes to its eastward progression. On the other hand, circulation associated with anomaly $C$ advects the filament
$A$ southwards, so favoring the cutoff process. Again, the effects of perturbations $B$ and $C$ are assessed quantitatively by performing model experiments in which anomalies are eliminated from the initial state following the PV inversion method presented in Sect. 4.

Experiment without anomaly $B$ develops a more intense cutoff low than the control run. Also, the low develops earlier and progresses farther eastwards and faster (Fig. 22). As a result of the different intensity and position of the upperlevel cutoff low, lower pressures are simulated in this case over the western Mediterranean. As a consequence, the high pressure system of central Europe and the Mediterranean LLJ are shifted northeastward. Then, the LLJ is impinging toward northwest Italy (Fig. 22) and the heavy precipitation in this experiment is obtained in the coastal lands, where the LLJ is directed (Fig. 24a). This confirms the leading role of the low tropospheric flow in supplying the necessary humidity to the coastal lands of the western Mediterranean basin. In terms of the stationarity, the effect of anomaly $B$ during the episode is to block the eastern progression of the cutoff depression and direct the persistent LLJ toward eastern Spain.

Finally, the experiment in which anomaly $C$ is eliminated from the initial conditions also simulates a more intense cutoff low than the control run. As expected, the lack of the southwards advection component over $A$ induced by anomaly $C$ produces a northwards shifting of the cutoff low trajectory (Fig. 23). The eastwards speed of the cutoff in this experiment is similar to the control run. The effect of the high level evolution on the LLJ is to slightly shift it northwards. Nevertheless, the high stagnancy is also observed in this experiment and a persistent flow toward eastern Spain is also obtained. As in the control run, the persistency of the easterly low-level winds and the mid-level southerly flow toward the Mediterranean flank of the Iberian Peninsula allows for the continuous supply of moisture and the production of 


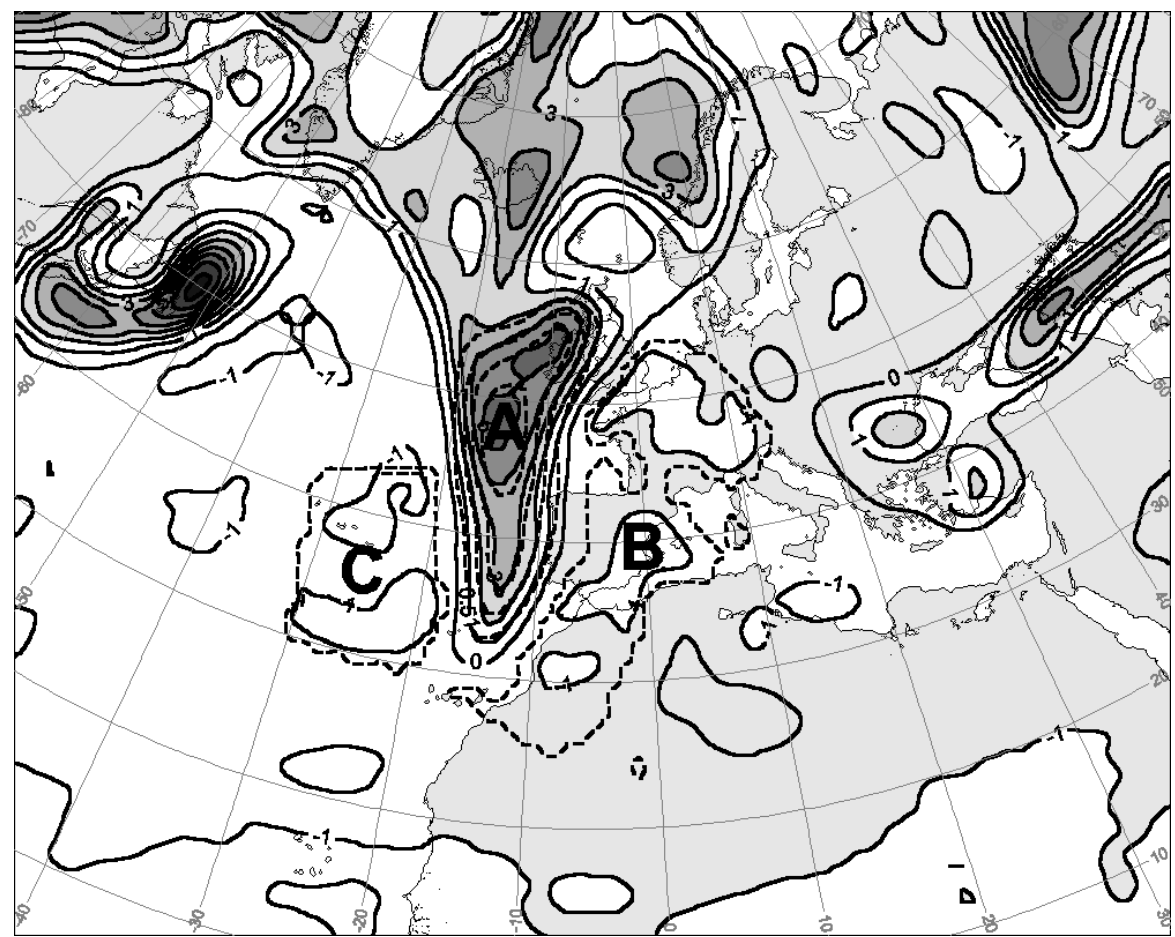

Fig. 21. PV perturbation field (PVU) for domain 1 at $300 \mathrm{hPa}$ calculated as the difference between the original PV field and an isobaric horizontal mean at each level, on 12:00 UTC, 20 October 2000. Labels A, B and C and the dashed line field depicts the anomalies referred to in the text. heavy precipitation amounts at the region where the LLJ is directed (Fig. 24b). This reveals that small errors in the representation of the latitudinal position of the cutoff low would have not affected significantly the forecast rainfall amounts, whereas a precise forecast of the precipitation location crucially depends on the accurate representation of the upperlevel dynamic structures.

\section{Conclusions}

A numerical study of the heavy precipitation event of 2124 October 2000 in eastern Spain has been presented. Total accumulated rainfalls up to $500 \mathrm{~mm}$ were registered at some locations, producing catastrophic flooding. Eight fatalities, as well as $100 \mathrm{M} €$ economical estimated loss, representing the resulting damage caused by the heavy rain.

The most important synoptic-scale feature characterizing the episode at mid to upper tropospheric levels was a cutoff low over north Africa, embedded in a $\Omega$-blocking structure, which favored the deepening of a surface low to the south of the western Mediterranean. The flow associated with this surface low, together with the northern high pressure center over Europe, generated an easterly LLJ over the western Mediterranean. Infrared satellite images show the formation of the cutoff low and the continuous development of convection over the eastern Iberian Peninsula during more than 4 days. Scattered convective cells are detected during the entire event, though signatures of a mesoscale convective system are observed over Valencia on 23 October.

Numerical simulation is used to analyze the physical processes which contributed to the intense rainfall genesis. The
MM5v3 model with 3 domains and a two-way nesting strategy is used to perform the experiments. The control run simulates the rainfall observations reasonably well, allowing one to rely on the model-simulated physical processes involved in the episode and perform a further diagnosis and numerical experimentation. The diagnosis of the event shows the installation and sustaining over the western Mediterranean basin of a warm and moist air mass at low levels, which favors the existence of convective and latent instabilization of the troposphere. In addition, a high increase of the water vapor content at all tropospheric levels is found. At upper levels, this is produced by the transport toward the western Mediterranean of very moist air trapped from the frontal system associated with its precursor trough. At low levels, the persistent easterly low-level jet continuously supplies the convective environment with moisture, evaporated mainly during the forecast period from the sea. As it is often observed in the heavy rainfall events in eastern Spain, not significant synoptic-scale forcing for upward motion is found in this case, thereby not opposing to the mesoscale ascent and triggering of the convective systems.

A PV inversion technique is applied to consistently modify the model initial conditions and to analyze the effects of certain dynamical structures on the episode evolution. A sensitivity experiment designed to analyze the effect of the intensity and location of the cutoff low reveals the crucial role played by the upper-level disturbance on the genesis and location of the LLJ and the further production of heavy rain. A weakened cutoff low remains to the southwest of the one obtained in the control run, thus, farther from the western Mediterranean. A confirmation of the capital role of the en- 

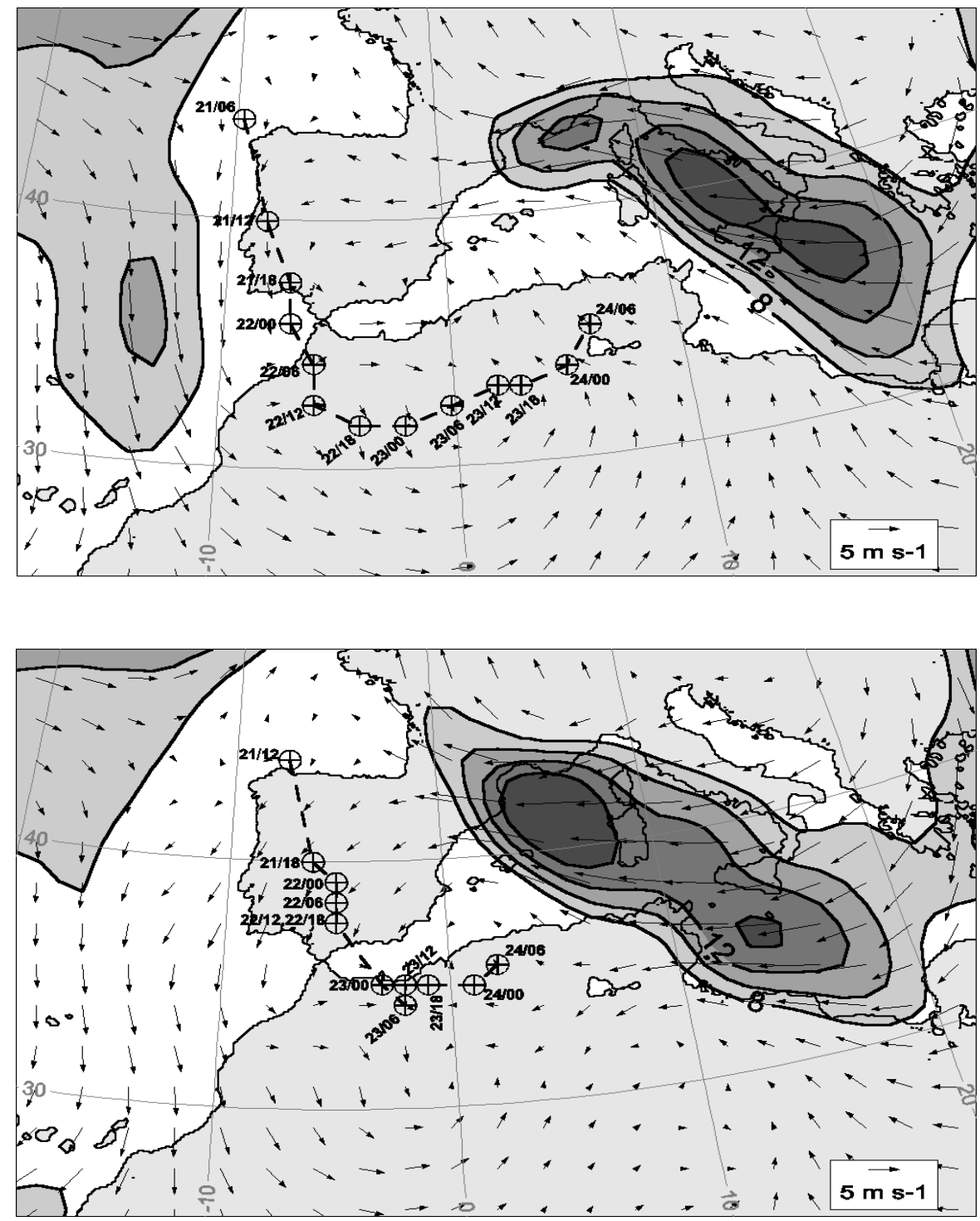

Fig. 22. As in Fig. 8 but for noB experiment. Note that for this experiment the cutoff low develops earlier and so its position at 06:00 UTC, 21 October 2000 is also depicted.
Fig. 23. As in Fig. 8 but for noC experiment. Note that the cutoff center locations of 22/12 and 22/18 coincide on the same model grid-point. hanced evaporation from the sea, induced by the LLJ, is obtained by the realization of a numerical experiment with no latent heat flux from the sea. In this experiment, a drastic reduction of the accumulated rainfall is obtained, despite the fact that the synoptic-scale evolution of the event is similar to the control run. Experiments with modified SST reveal that, even with reduced evaporation, substantial precipitation is obtained over land due to the long path followed over the sea by the low-level parcels before reaching eastern Spain. Referring to the role of the orography in this case, a sensitivity experiment has revealed that coastal orographic uplift acted to focus the precipitation, but no significant effect on the generation of the highly potentially and convectively unstable environment is obtained.

Finally, we addressed the effect of the relative geopotential highs sited east and west of the initial large-scale trough on the evolution of the cutoff low and the LLJ structure. Both the eastern and western positive height anomalies are shown to influence appreciably the evolution of the upper-level cut- off depression. In addition, the obtention of a LLJ pointing toward northwest Italy and heavy rainfall at the same area in one case, and the same behaviour but toward northeastern Spain in the other case, confirm the relation between the area where the LLJ is pointing to and the heavy rainfall prone zone.

In conclusion, based on the physical and dynamical factors identified in this study for the successful forecast of the heavy rainfall event, an accurate representation of the evaporation from the sea (i.e. with realistic boundary layer parameterizations and correct prediction of the sea surface temperature and near surface conditions), as well as the precise representation of the upper-level dynamical structures in the model initial conditions, appear to be crucial for an improvement of the heavy rainfall forecasts over the western Mediterranean basin.

Acknowledgements. This research was mainly developed in the framework of the WMO-WWRP "Mediterranean Experiment 


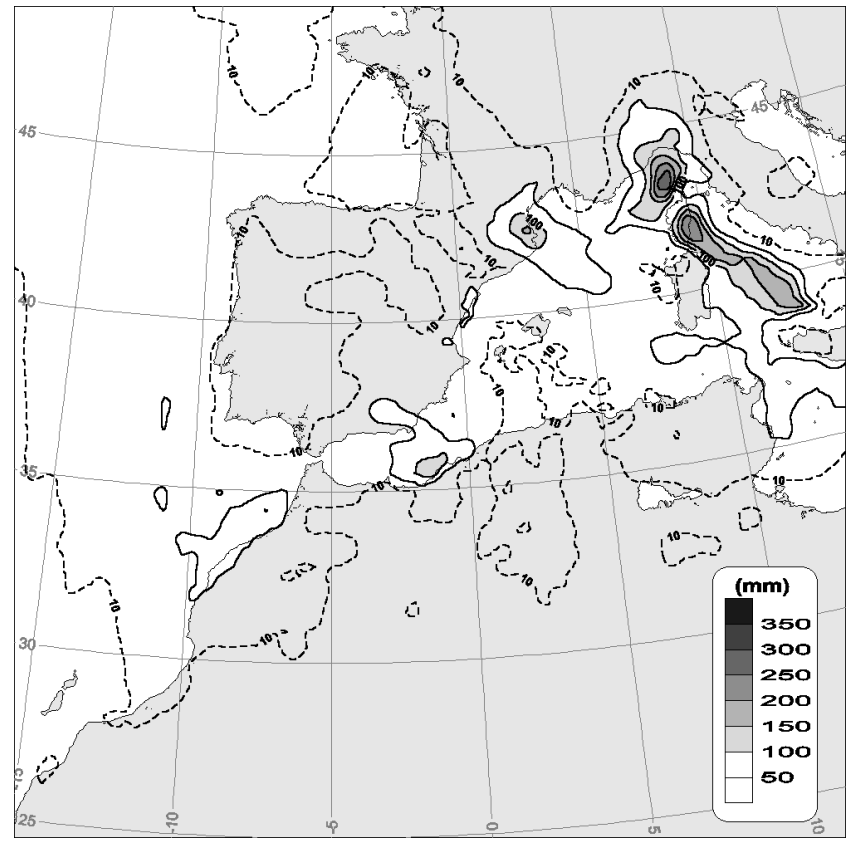

(a)

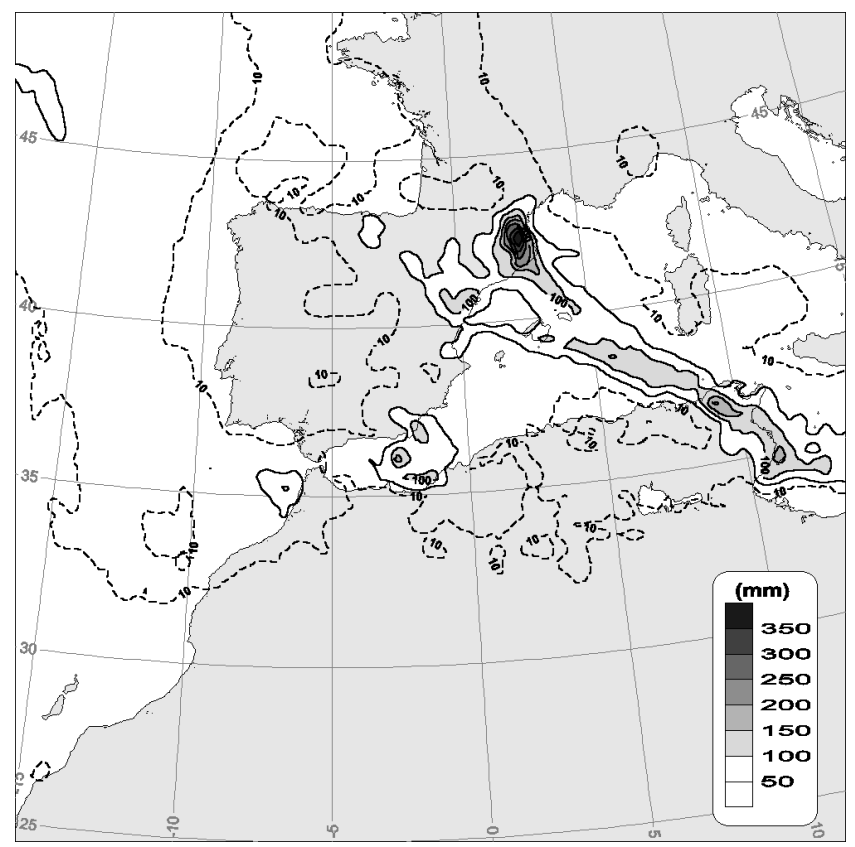

(b)

Fig. 24. As in Fig. 7c but for (a) noB and (b) noC experiments. Note the selection of domain 2 to present these fields in order to include the rainfall structure of western Italy, not captured by domain 3.

MEDEX” project. Satellite images and precipitation data were provided by the Instituto Nacional de Meteorología (INM) of Spain. Computer support provided by NCAR/Scientific Computer Division (which is sponsored by the National Science Foundation) for model data preprocessing is also acknowledged. We wish to thank the reviewers for their comments, which helped to clarify and improve this paper. This work has been partially supported by the CICYT CLI99-0269 grant.

Topical Editor J.-P. Duvel thanks B. Giordani and A. Buzzi for their help in evaluating this paper.

\section{References}

Benjamin, S. G.: Some effects of heating and topography on the regional severe storm environment, Ph.D. thesis, The Pennsylvania State University, 265 pp. [Available from University Microfil, 300 N. Zeeb Rd., P.O. Box 1346, Ann Arbor, MI 46801-1346.], 1983.

Charney, J. G.: The use of primitive equations of motion in numerical prediction, Tellus, 7, 22-26, 1955.

Davis, C. A. and Emanuel, K.: Potential vorticity diagnostics of cyclogenesis, Mon. Wea. Rev., 119, 1929-1953, 1991.

Doswell III, C. A.: The distinction between large-scale and mesoscale contribution to severe convection: A case study example, Wea. Forecasting, 2, 3-16, 1987.

Doswell III, C. A., Brooks, H., and Maddox, R.: Flash flood forecasting: An ingredients-based methodology., Wea. Forecasting, 10, 560-581, 1996.

Dudhia, J.: A nonhydrostatic version of the Penn State/NCAR mesoscale model: Validation tests and simulation of an atlantic cyclone and cold front, Mon. Wea. Rev., 121, 1493-1513, 1993.

Font, I.: Climatology of Spain and Portugal, Instituto Nacional de Meteorología, 296 pp., (In Spanish) Apartado 285, 28 071, Madrid. Spain, 1983.

García-Dana, F., Font, R., and Rivera, A.: Meteorological situation during the heavy rainfall event in eastern Spain in October 1982, Instituto Nacional de Meteorología, (In Spanish). Apartado 285, 28 071, Madrid, 1982.

Giordani, H. and Planton, S.: Modeling and analysis of ageostrophic circulation over the Azores oceanic front during the SEMAPHORE experiment, Mon. Wea. Rev., 128, 2270-2287, 2000.

Grell, G. A., Dudhia, J., and Stauffer, D. R.: A description of the fifth-generation Penn State/NCAR mesoscale model (MM5), NCAR Tech. Note NCAR/TN-398+STR, 1995.

Holton, J. R.: An introduction to dynamic meteorology. Third Edition, vol. 48 of International Geophysics Series, Academic Press, New York, 1992.

Homar, V., Ramis, C., Romero, R., Alonso, S., García-Moya, J., and Alarcón, M.: A case of convection development over the western Mediterranean sea: A study through numerical simulations, Meteor. Atmos. Phys., 71, 169-188, 1999.

Hong, S. Y. and Pan, H. L.: Nonlocal boundary layer vertical diffusion in a medium-range forecast model, Mon. Wea. Rev., 124, 2322-2 339, 1996.

Kain, J. S. and Fritsch, J. M.: A one-dimensional entraining/detraining plume model and its application in convective parameterization, J. Atmos. Sci., 47, 2 784-2 802, 1990.

Kain, J. S. and Fritsch, J. M.: Multiscale convective overturning in mesoscale convective systems: Reconcicling observations, simulations and theory, Mon. Wea. Rev., 126, 2 254-2 273, 1997.

Lin, Y. L., Farley, R. D., and Orville, H. D.: Bulk parameterization of the snow field in a cloud model, J. Clim. Appl. Meteorol., 22, 1065-1 092, 1983.

Llasat, M. C.: Heavy rain events in Catalonia: Genesis, evolution and mechanism, Ph.D. thesis, University of Barcelona, (In Span- 
ish). Avda. Diagonal, 647. 08028 Barcelona. Spain, 1987.

Ramis, C., Llasat, M. C., Genovés, A., and Jansá, A.: The October 1987 floods in Catalonia: Synoptic and mesoscale mechanisms, Meteor. Appls., 1, 337-350, 1994.

Ramis, C., Romero, R., Homar, V., Alonso, S., and Alarcón, M.: Diagnosis and numerical simulation of a torrential precipitation event in Catalonia (Spain), Meteorol. Atmos. Phys., 69, 1-21, 1998.

Rockwood, A. A. and Maddox, R. A.: Mesoscale and synoptic interactions leading to intense convection: The case of 7 june 1982, Wea. Forecasting, 3, 51-68, 1988.

Romero, R., Guijarro, J., Ramis, C., and Alonso, S.: A 30-year (1964-1993) daily rainfall data base for the spanish mediterranean regions: first exploratory study, Int. J. Climatol., 18, 541560, 1998a.

Romero, R., Ramis, C., Alonso, S., Doswell III, C. A., and Sten- srud, D.: Mesoscale model simulations of three heavy precipitation events in the western Mediterranean, Mon. Wea. Rev., 126, 1859-1881, 1998b.

Romero, R., Doswell III, C. A., and Ramis, C.: Mesoscale numerical study of two cases of long-lived quasistationary convective systems over eastern spain, Mon. Wea. Rev., 128, 3731-3751, 2000.

Stensrud, D. J. and Fritsch, J. M.: Mesoscale convective systems in weakly forced large-scale environments. Part I: Observations, Mon. Wea. Rev., 121, 3326-3344, 1993.

Tao, W. and Simpson, J.: Goddard cumulus ensemble model. Part I: Model description, Terrestrial, Atmospheric and Oceanic Sciences, 4, 35-72, 1993.

Weisman, M. L. and Klemp, J.: Characteristics of isolated convective storms, in Mesoscale Meteorology and Forecasting, edited by E. P. S. Ray, 331-358, Amer. Meteor. Soc., 1986. 